\title{
Análisis y resultado comparativo del control oficial de flujos en la emigración española a la RFA (1960-1973)
}

\author{
Analysis and comparative results of flow control in the \\ Spanish emigration to the FRG (1960-1973)
}

\author{
GLORIA SANZ LAFUENTE \\ Universidad Pública de Navarra
}

\begin{abstract}
RESUMEN
El objetivo de este trabajo es analizar el papel de las instituciones en el volumen, cualificación

y composición por sexos de la población emigrante mediante el estudio del caso de la RFA entre 1960 y 1973. En este sentido, se trata

de ofrecer una aportación estadística, que contrasta los datos de la emigración española con los resultados de diversas fuentes alemanas y suministra resultados de una forma comparada con otros países. El estudio considera que en la mayoritaria emigración laboral a la RFA se combinaron la situación estructural de los mercados de trabajo de ambos países, las decisiones individuales de emigrantes y empresas y también, la actividad de una infraestructura burocrática oficial destinada a la gestión y al control de flujos en un periodo de crecimiento, en el que se asistió a una liberalización controlada de las políticas

migratorias, a acuerdos de emigración y a procesos de negociación entre el país de origen y de destino de la emigración.
\end{abstract}

PALABRAS CLAVE: Rfa, Emigración Española, Politica de Emigración, Género, Mercado de Trabajo

Códigos JEL: N, N34, N44, 015

\section{ABSTRACT}

This article makes a contribution to Spanish migration to the FRG (1960 1973) using statistical data supplied in both countries in a comparative perspective with other home countries. The aim of this paper is to study the role of institutions in the volume, qualification and gender composition of the migrant population through this case study. Our paper concluded that labour migration to the FRG combined labour market structure of both countries, individual decisions of agents and firms, and a bureaucratic official infrastructure for the management and control of migration flows, which was based on a controlled liberalization of migration policies as well as on a bilateral agreement and on continuous bargaining processes during a growth period.

KEY WORDS: FRG, Spanish Migration, Migration Policy, Gender, Labour Market

JEL Codes: N, N34, N44, 015 


\section{Introducción ${ }^{1}$}

$\mathrm{R}$ ecientemente, el estudio de la emigración posee un carácter integrador al proponerse una investigación de carácter interdisciplinar de los fenómenos micro, en lo que Massey denominó causación acumulativa de los procesos de emigración ${ }^{3}$. En esta acumulación de factores destaca el papel del capital social de los emigrantes, que estaría formado por las redes de emigración, entendidas como interacciones interpersonales que suministran información, recursos e influyen en un flujo migratorio y también, por lo que se han dado en llamar instituciones de la emigración ${ }^{4}$. Dentro de estas instituciones, el papel de los Estados, como organización de carácter formal y normativa, y el de las instituciones informales -prestamistas, encargados del transporte clandestino o mediadores en la gestión de contratos con empresas- se convierten en agentes con intereses propios, que limitan o estimulan el conocimiento y el acceso a la información y a los recursos necesarios para emigrar.

La política de emigración e inmigración y la actividad del Estado constituyen uno de los ejes en el análisis económico de los desplazamientos de la población ${ }^{5}$. Uno de los debates que forma parte del estudio de los movimientos migratorios es el que se adentra en el fenómeno de la irregularidad ${ }^{6}$ y en la capacidad de las instituciones políticas para controlar el volumen de los flujos migratorios o su composición ${ }^{7}$. En este sentido, Timothy J. Hatton y Jeffrey G. Williamson han subrayado la necesidad de conocer mucho más sobre las diferencias que generan las políticas migratorias y

[Fecha de recepción del original, junio de 2007. Versión definitiva, de noviembre 2008].

1 Este trabajo de investigación pertenece al proyecto Die Auswanderung der spanischen Agrarbevölkerung nach Deutschland 1955-1975. Generelle und regionale Aspekte, realizado con el apoyo del Institut für Europäische Geschichte en Maguncia (Alemania). Una primera versión de sus resultados se presentó en el marco del coloquio de dicha institución. Agradezco las numerosas aportaciones de los evaluadores de la revista Investigaciones de Historia Económica, de Joseba de la Torre y de José Miguel Lana, que sin duda, han contribuido a mejorar el texto inicial presentado.

$2 \quad$ Bretell y Hollifield (2008).

3 Massey et alii (2002), pp. 42 y ss. Massey, Arango et alii (1993), pp. 431-466. A la teoría de los mercados duales (Piore, 1979), o a la consideración del crecimiento demográfico (Livi Bacci, 1972) como factor de la emigración se han unido, más delante, las aportaciones de la nueva economía de la emigración. Ésta se adentraba en el análisis de la decisión de emigrar partiendo de la consideración de los hogares como unidades de decisión y aportando la noción de pobreza relativa y de información asimétrica dentro de un grupo (Stark, 1993). Un buen resumen en Silvestre (2000), p. 157-194.

Goss y Lindquist (1995), p. 345.

Zimmermann y Bauer (2002), pp. 435-508.

Düwell (2006).

Zolberg (1981) (2006), Cornelius, Philip y Hollified (1994), Money (1999), Massey y Taylor (2004), Messina (2007). En lo referente a la posibilidad de control estatal existen posturas opuestas. Saskia Sassen hace referencia a las crecientes dificultades de control con que se encuentran los estados frente al fenómeno migratorio. Sassen (2001). Con un posición opuesta, Joppke (1998). 
sus efectos reales sobre el flujo migratorio ${ }^{8}$. Los estudios empíricos de caso representan, en este sentido, una importante aportación.

El objetivo de este trabajo es analizar la negociación de la administración alemana y española y ofrecer una aportación estadística contrastando los datos ofrecidos por diversas fuentes en ambos países. Se trata de estudiar el control del volumen y composición de los flujos de la emigración española entre 1960 y 1973. En definitiva, el artículo trata de analizar la evolución de la emigración oficial a la RFA -la denominada emigración asistida- y de la emigración al margen de este control de una forma comparada con otros países y también de estudiar el papel de las instituciones políticas en la cualificación y en la composición por sexos de la población emigrante. Las negociaciones y el desarrollo de la emigración al margen de los cauces legales, consentida en parte por las dos administraciones, está relacionada con las características y necesidades de los mercados de trabajo de ambos países. Este hecho estuvo relacionado, además, con un interés mutuo por el mercado de trabajo cualificado y por las profesiones consideradas "femeninas".

En Europa occidental, las políticas de inmigración y emigración fueron muy heterogéneas tras la posguerra, si bien, todas ellas practicaron una liberalización controlada desde mediados de los cincuenta hasta comienzos de los setenta ${ }^{9}$. El sistema de cuotas y de visados alrededor de la demanda de una determinada cualificación laboral siguió formando parte de las políticas de inmigración de varios países occidentales después de la Segunda Guerra Mundial ${ }^{10}$. Junto a ellos se estableció un sistema de trabajadores invitados -guest workers/ Gastarbeiter -, que funcionó por medio de acuerdos bilaterales de emigración y de sistemas de gestión conjunta de contratación entre el país de origen y el de destino. Si bien, en la práctica, estos sistemas se entremezclaron, la RFA sería un ejemplo de este último tipo de gestión de la política migratoria hasta su supresión en $1973^{11}$. En este caso, la emigración transcurrió por cauces burocráticos de gestión y de negociación entre dos países, generando una infraestructura oficial formada por funcionarios federales asentados en Madrid -Comisión Alemana-, que recibían las demandas de empresas, y por funcionarios del Instituto Español de Emigración (IEE), que pretendía controlar la oferta de emigración laboral a la RFA. El Acuerdo entre el Estado español y la República Federal de Alemania sobre migración, contratación y colocación de trabajadores españoles, firmado en 1960, sería uno de esos ejemplos ${ }^{12}$.

$8 \quad$ Hatton y Williamson (2005), p. 214.

$9 \quad$ Hollifield (1992), Hatton y Williamson (2007).

10 Hatton y Williamson (2005), p. 219-221.

11 En el caso de Suiza, por ejemplo, se gestionaron las entradas a través de acuerdos bilaterales y de una política basada en cuotas con diferentes permisos de trabajo según su duración (temporal de 9 a 12 meses), permisos de un año y de residencia definitiva. Gross (2007), p. 185, Herbert (2001). 
El acuerdo de emigración con la RFA no era el único llevado a cabo con países europeos ya que también se firmaron otros con Bélgica (1956), Francia, Países Bajos y Austria (1961) y Suiza (1964). Tomando como referencia las series de emigración disponibles con los datos de los países de destino, entre 1960 y 1970 la RFA (33,9\%), Francia $(31,7 \%)$ y Suiza (19\%) representaron un promedio del $84,6 \%$ de la emigración hacia Europa ${ }^{13}$. Los trabajadores españoles ascendían al 15\% de la mano de obra extranjera en la RFA en 1965, detrás de Italia y Grecia. Este porcentaje descendió al 6\% en 1975, en medio del incremento en la llegada de trabajadores turcos y yugoslavos.

El grado de control de los flujos migratorios, que se ejerció por parte del Instituto Español de Emigración (IEE) en su gestión de la emigración asistida a Europa, y los datos ofrecidos por éste fueron ya objeto de valoración en los análisis sobre la emigración hacia Europa que se publicaron antes de $1975^{14}$. En esta literatura se aludía a la escasa fiabilidad de las cifras oficiales españoles y a la existencia de emigración al margen de los canales de la emigración asistida. Francisco Sánchez López, completaba ya en 1969 la información oficial, con series procedentes de los países europeos de destino de la emigración española y también los estudios posteriores, llevados a cabo desde la geografía y la sociología, señalaron la escasa validez de las cifras oficiales, e incorporaron datos comparativos procedentes de los países de destino, que este trabajo trata de contrastar y de completar para el caso concreto de la RFA ${ }^{15}$. El análisis de Carmen Ródenas también ponía de manifiesto la escasa fiabilidad de los datos oficiales de la emigración a Europa, utilizando información estadística de la emigración asistida del IEE y las estimaciones de emigración real, que realizó esta institución ${ }^{16}$.

Aunque ya existían estudios regionales previos, fue en los años noventa cuando se reavivó el estudio histórico de la emigración europea ${ }^{17}$. Desde entonces, el análisis del papel del Estado en la gestión de flujos migratorios ha formado parte de aproximaciones generales y también, de investigaciones, publicadas recientemente sobre la emigración a Francia, a la RFA y a Bélgica ${ }^{18}$. Si la necesaria revisión de los datos ofrecidos por el IEE ya aparecía en la bibliografía existente, la labor de negociación con los distintos países con los que se firmaron acuerdos de emigración y el papel de estas instituciones laborales españolas y del resto de países europeos en el control y en la composición de los flujos migratorios han sido introducidos por estos estudios,

\footnotetext{
$13 \quad$ Nicolau (2005), p. 142.

14 García Fernández (1965), p. 78, Sánchez López (1969).

15 Pujol Antolín (1979), pp. 69 y ss. La comparación con datos procedentes de otros países en Cardelus y Pascual (1979). Sobre la emigración a la RFA Garmendia (1970) y (1981), pp. 245-286. Otros análisis sociológicos generales Ministerio de Trabajo (1986). Harms (1986), pp.49-68. “Desde la economía Antolín (1992)". Rodenas Calatayud (1994).

Alonso (1983), Fernández Asperilla (1988), Vilar y Vilar (1999).

Babiano y Fernández Asperilla (2002), Fernández Vicente (2004), pp. 228-261. En especial para la RFA el elaborado estudio de Sanz Díaz (2004). También referencias en (2006), (en prensa a) (en prensa b). Rodríguez Barrio (2006), pp. 99-114 y Fernández Asperilla (2006).
} 
en especial, en las aportaciones de María José Fernández Vicente y de Carlos Sanz Díaz. En Alemania, si bien aparecen alusiones en aquellos pocos análisis realizados sobre el caso de la emigración española, ha sido la abundante bibliografía sobre política migratoria completada con estudios posteriores, la que ha permitido un mayor conocimiento a los sistemas de gestión oficial de flujos ${ }^{19}$. A ésta se suman los análisis económicos generales del fenómeno migratorio, que también recogen referencias a esta gestión oficial ${ }^{20}$. Junto a todo ello, son las monografías más novedosas las que se aproximan con mayor profundidad a temas específicos, como son los procesos de negociación con los países de origen de la emigración y el papel del género en la gestión oficial de los flujos migratorios ${ }^{21}$.

\section{Fuentes estadísticas para el estudio de la emigración en la RFA y en España}

Incluso en un periodo como el que nos ocupa, en el que las estadísticas se asentaron como instrumento oficial y académico de conocimiento, los movimientos migratorios se revelaron en la como una variable de difícil aprehensión cuantitativa, debido a la escasa armonización y estabilidad de los conceptos y métodos utilizados en la recogida de datos y a las características propias de fenómenos migratorios -ilegalidad, remigración, movimientos temporales o desplazamientos entre varios países-, que dejaron escaso rastro en las series temporales compiladas ${ }^{22}$. La combinación de fuentes procedentes del país de origen y del de destino resulta una vía para aproximarse con más garantías al fenómeno migratorio en su dimensión cuantitativa y cualitativa. En el caso de la emigración a Europa ya se realizó este esfuerzo por varios autores desde finales de los sesenta, mostrando la escasa validez de las estadísticas oficiales españolas del flujo emigratorio ${ }^{23}$. Las series cuantitativas que se utilizan en este trabajo provienen de contrastar los datos que suministra el Instituto Español de Emigración del Ministerio de Trabajo con las series que provienen de la Oficina Federal de Colocación y Seguro de Desempleo -Bundesanstal für Arbeitsvermittlung und Arbeitslosenversicherung (BAVAV) -más adelante Oficina Federal de Trabajo -Bundesanstalt für Arbeit (BAA)- y

\footnotetext{
19 Mertins (1984), Breitenbach (1982), Romano-García (1995), Bethlehem (1982), Dohse (1985), Steinert (1995), Herbert (2001), Sonnenberger (2003), Schönwälder (2003), pp. 123-144, Sonnenberger (2003), pp. 145-174. Bauer y Zimmermann (1996), pp. 74-108, Karras y Chiswick (1999), Zimmermann (2004) (2007).

Destacando las relaciones diplomáticas por encima de otros factores Knortz (2008). Sobre la inmigración de mujeres Mattes (2005).

22 Poulain (1991), pp. 115-138.

23 Con fuentes del BAVAV entre otros, Sánchez López (1969), González Paz (1971), Cardelus y Pascual de Sans (1979), Pascual de Sans (1985).
} 
de la Oficina Federal de Estadística -Statistiches Bundesamt- en la RFA ${ }^{24}$. El Instituto Español de Emigración se convirtió desde su creación, en 1956, en el principal organismo relacionado con la gestión y contabilización de flujos migratorios ${ }^{25}$. Los datos oficiales ofrecidos por el IEE recogen la emigración asistida e identifican "emigración" y "contratación oficial". Incluso el director de esta institución señalaba en 1966 que..." los datos de emigración asistida del Instituto son los únicos con un respaldo estadístico cierto, pero no comprenden toda la emigración" 26 . El propio IEE ofrecía estimaciones de la emigración más allá de sus propias cifras ${ }^{27}$. Estas estimaciones oficiales tienen escasa validez para el caso concreto de la RFA, si contrastamos la información suministrada con la tendencia y volumen de los flujos, que aparecen en las fuentes oficiales alemanas y españolas (Anexo Cuadro 1) ${ }^{28}$.

En el caso de la RFA, dos son las fuentes principales de información cuantitativa ya conocidas. El BAVAV/BAA contabilizó las llegadas anuales por medio de la contratación oficial y también, aquellas llegadas al margen, por medio de otras vías que derivaban en un permiso de trabajo en la RFA entre 1960 y 1973. En definitiva, se incluyó en las series toda la emigración laboral: aquellos emigrantes que llegaron de forma oficial -asistidos- y los que llegaron por los otros dos caminos paralelos: Por un lado, solicitando un visado de trabajo en los consulados alemanes en España (segundo camino) y por otro, los que lo hacían con un visado de turista y regularizaban su situación en la RFA a posteriori con un permiso de trabajo y de residencia (tercer camino). En el caso de la emigración no asistida, la fuente ofrece cifras globales distribuidas por países en las que, sin embargo, no se hace referencia a la composición por sexos. En 1973 se cerraba la vía de la contratación asistida gestionada por el BAVAV/BAA. Entre 1974 y 1975 la información de las nuevas llegadas proviene de la estadística de trabajo -Arbeitsstatistik- del Ministerio de Trabajo, por medio de la contabilización de permisos de trabajo.

Junto a esta información también se han utilizado las series procedentes de la Oficina Federal de Estadística. La información sobre entradas anuales entre España y la RFA -pasos de frontera- permite salir de los datos de emigración laboral del Ministerio de Trabajo Federal y aproximarnos al flujo de población desplazada desde España hacia la RFA diferenciando entre sexos. Estos datos permiten aproximarnos a los desplazamientos laborales al margen de la gestión oficial y fenómenos de reagrupación familiar. La limitación que presenta esta fuente no es otra que el contabi-

\footnotetext{
24 Las estadísticas del SOPEMI de la OCDE y de la ONU, reproducen los datos suministrados por los diferentes países de origen de la emigración. Con los datos de la ONU y SOPEMI Venturini (2004). Sobre la validez de las cifras del SOPEMI, King y Rybaczuk (1993), p. 19. IEE (1965a).

Ministerio de Trabajo (1966d), p, 19. ; IEE (1965b).

Ródenas (1994), p. 83.

Sanz Lafuente (en prensa a).
} 
lizar todas las salidas y entradas entre la RFA y España en un año. En este sentido, la doble entrada o salida de una misma persona -vacaciones o paro, por ejemploqueda registrada igualmente. Este aspecto de la doble contabilización tampoco hay que descartarlo, sin embargo, en las estadísticas laborales del BAVAV/BAA ${ }^{29}$. Dejando al margen las cifras de emigración estimadas por el IEE hasta 1966, las tres series principales muestran diferencias en el volumen de emigración, pero mantienen una amplia similitud de las tendencias durante este periodo ${ }^{30}$.

Las fuentes cualitativas están compuestas por los informes de la Comisión Alemana depositados en el Bundesarchiv en Coblenza, que recogen información sobre las actividades de contratación en España entre 1960 y 1973, y por la documentación referida a España depositada en el Archivo de Caritasverband en Friburgo. Resultan de gran importancia cualitativa las dos investigaciones llevadas a cabo por el Ministerio de Trabajo federal sobre la ocupación de los trabajadores extranjeros en la RFA, publicadas en 1969 y de 1973. La literatura contemporánea procedente del Instituto Español de Emigración del Ministerio de Trabajo en España servirá de base documental para perfilar los temas que a continuación se exponen. Primero se analiza el control oficial de la emigración laboral hacia la RFA de forma comparada con otros países y se recogen las diferentes vías de acceso a la emigración de hombres y mujeres. Posteriormente, se estudia papel de la cualificación de los emigrantes en esa gestión oficial, comparando los resultados de España con los de otras áreas de origen de la emigración.

\section{Sobre el control oficial de la emigración: una aproximación compa- rativa}

La liberalización de las políticas migratorias de la posguerra europea no llevó a la libre circulación del factor trabajo y a la desaparición de los controles de fronteras en el periodo de crecimiento ${ }^{31}$. En medio de la influencia de autores como W. A. Lewis y de su teoría del crecimiento por medio de una oferta ilimitada de mano de obra, C.P. Kindleberger recogía en 1967 el importante papel que desempeñaba la interconexión de los mercados laborales del sur, norte y centro de Europa y el papel de las

29 Sobre la doble entrada tras el paro o las vacaciones y la contabilización de "antiguos emigrantes" como nuevos BA B 119/ 3067 B2 Neuenreise ausländischer Arbeitnehmer in de BRD... 7.07.1967. También BA B 119/ 3067b2 Einreise auf dem sogenannten zweiten Wege...13.09.1967.

30 El coeficiente de correlación para el periodo 1960-1973 entre emigrantes asistidos con contrato oficial y las cifras globales del BAVAV/BA es de 0.910. Entre los asistidos y el flujo migratorio es de 0.927 y entre las cifras del BAVAV/BA y el flujo migratorio es de 0.967.

31 Zolberg (1981). 
políticas migratorias en el crecimiento industrial de la posguerra europea ${ }^{32}$. La emigración europea afectó y puso en relación a países con situaciones políticas y económicas bien diferenciadas, que habían quedado en el eje de influencia del oeste con marcadas diferencias de desarrollo económico en su interior, como era el caso de Italia y Grecia o España, y consiguió, más adelante, abarcar a otros más cercanos al otro lado del telón de acero como Yugoslavia ${ }^{33}$. En conjunto, los emigrantes desplazados a la RFA entre 1956 y 1972 tenían un claro predominio intraeuropeo con cifras superiores al 90\%, incluyendo a Turquía. El desplazamiento estuvo marcado por una liberalización de las políticas migratorias en España y en la RFA y por un contexto internacional -en especial en la OCDE, que también tendía hacia esta liberalización controlada hasta la crisis de $1973^{34}$.

El mercado de trabajo alemán y el español comenzaron sus "relaciones" antes de que el IEE y la Comisión Alemana en Madrid lo hicieran de forma oficial y comenzasen a organizar los flujos con la firma del acuerdo en $1960^{35}$. Antes de esa fecha ya se habían desplazado a la RFA los primeros grupos de trabajadores y estas relaciones continuaron, aunque de forma más limitada, después de la finalización de las actividades oficiales de contratación de la Comisión Alemana en 1973. Junto a la actividad de los primeros grupos desplazados para alimentar el fenómeno migratorio en su entorno cercano, tanto los funcionarios federales como los empresarios alemanes en busca de mano de obra se convirtieron en difusores de una "opinión pública" favorable a la emigración y de una imagen de éste país como receptor de trabajadores desde comienzos de los años 60 . Todo ello se llevaba a cabo en estrecha colaboración con los medios de comunicación en España, que suministraban informaciones sobre demandas de trabajo y la emigración, y bajo el apoyo, tutela y gestión del IEE ${ }^{36}$.

La labor de los funcionarios federales se desarrollaba, además, en colaboración con las autoridades del IEE, con las delegaciones provinciales del mismo y con res-

32 Lewis (1954), pp. 139-191, Kindleberger (1967), Castles y Kosack (1973), Tapinos (1974), Navarro López (1981), pp. 15-40.

$33 \quad$ Novinscak (2007), pp. 141-161.

34 OECD (1975), (1978). Sobre la liberalización controlada de la política migratoria española, Fernández Asperilla (1998), Kreienbrink (2004), Fernández Vicente (2006), Hatton y Williamson (2007), p. 220 y 221.

35 Antes de la firma del acuerdo, en otoño de 1959, un representante de la empresa textil Johann Wülfing \& Sohn de Remscheid-Lennep, se ponía en comunicación con Luis Enrique Sorribes, agregado laboral en Bonn, para buscar trabajadores españoles. Este último contactaba con Miguel de Lis, delegado de Trabajo en Salamanca y organizaba una primera salida de trabajadores desde Béjar. Sonderdruck der Werkzeitschrift "Spindel und Schüzten", 1961, p. 2. Otras referencias en Sanz Díaz (2004).

36 BA B/119/ 3020 Erfahrungsbericht...1965.Anwerbung und Vermittlung ...1965. IEE (1966a), p. 12. En mayo de 1960 la Comisión Alemana hacía referencia a la propaganda necesaria para estimular la emigración y en 1965 el corresponsal del Frankfurter Allgemeine Zeitung servía a los funcionarios del Ministerio de Trabajo alemanes como puente de relación con censores y periodistas españoles, para llevar al espacio público su labor de gestión de la contratación laboral en la RFA. BA B/119/ 3069 Anwerbung und Vermittlung...27.05.1960. B/119/ 3066B2 Anwerbung und Vermittlung... 14.01.1965. 
ponsables del sindicalismo vertical - Servicio Nacional de Encuadramiento y Colocación (SNEC) de Sindicatos ${ }^{37}$. Esta dinámica de emigración en masa gestionada desde ambos Estados -la denominada emigración asistida- se desarrolló entre 1960 y 1973 con la fuerte reducción coyuntural que supuso la crisis de 1967, pero no abarcó, sin embargo, la totalidad de los flujos de emigración que llegaron a la RFA ${ }^{38}$. Sobre todo en los primeros años, la llegada de emigrantes discurrió en un porcentaje nada desdeñable al margen de la emigración asistida, es decir, fuera del sistema de contratación y de gestión de desplazamientos. La denominada emigración asistida fue, en definitiva, una parte de la emigración. El grado de control del proceso se incrementó, pero mantuvo al comienzo, una dinámica propia al margen de los cauces oficiales. Si en 1960 un 62\% de los emigrantes españoles a la RFA utilizaba caminos "al margen" del canal oficial, este porcentaje había pasado a un 11\% en 1973. En términos generales, entre 1960 y 1973, alrededor de un 30\% de la emigración laboral a la RFA habría llegado al margen de la contratación oficial. Si en lugar de la emigración laboral comparamos el flujo de emigración anual con las cifras oficiales de contratación, estas últimas representarían un $54 \%$ del flujo de entradas de población española.

A lo largo de estos años se generaban, además, diferentes concepciones sobre lo que significaba la "ilegalidad" en la emigración, en la RFA y en España, y vías muy plurales en el desplazamiento ${ }^{39}$. Las razones que los propios emigrantes señalaban para utilizar estos cauces al margen de la vía oficial eran varias. Las más habituales eran evitar esperas y controles administrativos -cuatro semanas en 1963 desde la pre-selección hasta la selección definitiva -, aprovechar la posibilidad de organizar la salida por sí mismo, evitar posibles restricciones a la salida por diferentes motivos -controles sanitarios de la Comisión Alemana o políticos en el caso del IEE, como era la presentación del certificado de penales, por ejemplo- y gestionar el contrato de trabajo por medio de parientes y amigos de confianza ya residentes en la RFA. También las empresas alemanas buscaban vías más rápidas. En 1964, en la reunión entre los representantes del Ministerio de Trabajo Federal y un grupo de empresarios que contrataban trabajadores españoles se señalaba que los caminos paralelos eran más ágiles ${ }^{40}$. Utilizar visados de trabajo obtenidos en los consulados alemanes -segundo camino - y entrar en la RFA con un visado de turista -tercer camino- fueron las vías "al margen" más utilizadas ${ }^{41}$.

El IEE solamente reconoció como legal la contratación oficial, considerando como ilegal o irregular el resto de las vías. Mientras, el Ministerio de Trabajo Federal

BA B/119/ 3018 Erfahrungsbericht...1968.

Sobre la limitación de la contratación durante la crisis BA B119/ 4146 An alle Dienststellen...02.05.1967.

En propio IEE reconocía que la emigración asistida no comprendía toda la emigración a la RFA y que la llegada al margen existía pese a que "no se ajusta al Acuerdo vigente". Ministerio de Trabajo (1966d), p. 19.

BA B 119/ 3066B2 Sitzung betreffend Anwerbung spanischer Arbeitskräfte am 5. März 1964 in Bonner Büro.

Sanz Díaz (2006), p. 294. 


\section{GRÁFICO 1}

COMPARACIÓN GRÁFICA DEL FLUJO DE EMIGRACIÓN ANUAL A LA RFA (1960-1975) CON LA CONTRATACIÓN ASISTIDA (1960-1973) Y CON LA EMIGRACIÓN LABORAL LLEGADA

\section{A LA RFA MEDIANTE CAUCES ASISTIDOS Y NO ASISTIDOS}

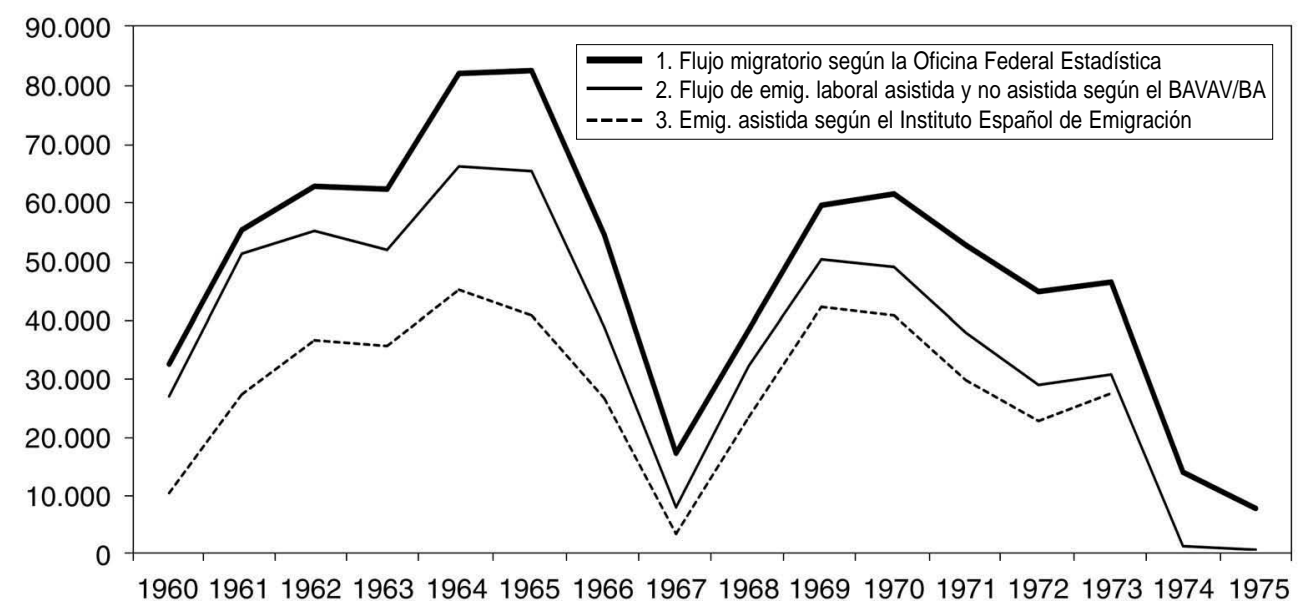

Unidad de cuenta: 1. Emigrantes contabilizados por medio de las entradas y salidas a través de la frontera. 2. Suma de emigrantes llegados por la vía oficial (1) y permisos de trabajo gestionados a posteriori en la RFA. 3. Emigrantes que llegan bajo la gestión del IEE y de la Comisión Alemana en Madrid.

Fuente: Erfahrungsberichte BAVAV/BA, Statistiches Bundesamt.1960 y 1961: 96,6 \% y 97,8\% de la población procedente de España que se contabiliza es española.1962-1975: 100\% de la población procedente de España que se contabiliza es española.

también reconocía como legal el segundo camino por medio de los visados de los consulados alemanes y la emigración con visados de turistas, si bien sujeta en este último caso a intereses del mercado laboral alemán ${ }^{42}$. Las autoridades españolas mostraron un interés por controlar estos flujos y consideraban ilegales las vías "al margen" de la emigración asistida, si bien la consideración positiva de la emigración y su vinculación al desarrollo económico favoreció una cierta regularización de la "ilegalidad" en ciertos momentos y la tolerancia durante todo el periodo. La consideración de "legalidad" o "ilegalidad" adquirió diferentes lecturas oficiales en la teoría y en la práctica en ambos países y estuvo sujeta a continuos procesos de negociación e intereses propios del mercado de trabajo en la RFA y en España ${ }^{43}$.

42 Sanz Díaz (en prensa).

43 BA B119/3352B1 Resumen de la reunión 6.02.1963. 
En las conversaciones mantenidas en Madrid en 1961 entre representantes del Ministerio de Trabajo -IEE y Dirección General de empleo -, y del SNEC de sindicatos junto a los funcionarios federales de la Comisión Alemana, se establecía, por ejemplo "la solución al problema de los españoles que están en Alemania con pasaporte ordinario". Estos emigrantes se habían desplazado al margen de los sistemas de contratación oficiales y su situación requería una solución. Por un lado, los trabajadores españoles que estaban ya en la RFA con pasaporte ordinario y habían obtenido allí el permiso de residencia podrían trabajar y cuando regresasen de vacaciones serían provistos de un visado de salida por parte de la Dirección General de Seguridad para poder regresar de nuevo a la RFA. Por otro, los que habían entrado en la RFA con visado de turista y habían conseguido un contrato allí "al regresar a España obtendrá por parte de las autoridades españolas un visado y las máximas facilidades para que pueda cumplir el contrato, previo los trámites necesarios cerca de la Comisión Alemana para obtener su Carta de Legitimación". En este caso concreto, la diferente percepción de la legalidad en la RFA y en España estuvo sujeta a un proceso de negociación y tanto la Comisión Alemana como el IEE estuvieron de acuerdo en la regularización ${ }^{44}$. En medio de continuos acuerdos de emigración con varios países, la legislación sobre extranjeros de 1965 en la RFA limitó el segundo camino para peones sin cualificar, pero éste se mantuvo para grupos más demandados en el mercado de trabajo alemán, como las mujeres y trabajadores cualificados, a la vez que se establecía un mayor control de la inmigración por medio de visados de turista. A partir de 1972 las limitaciones se ampliaron al resto de los grupos ${ }^{45}$.

La postura oficial española estuvo jalonada por la combinación de dos elementos. De un lado, una oposición a los caminos de la emigración al margen de la gestión oficial y de otro, el pragmatismo que conllevaba considerar la emigración como un necesario instrumento del desarrollismo ${ }^{46}$. De ahí que la Dirección General de Empleo se opusiera a reconocer como legal la utilización de visados de los consulados alemanes para desplazarse a la RFA en 1961, mientras se apoyaban regularizaciones de emigrantes llegados al margen a comienzos de los 60 o se toleraba, en la práctica, la emigración con visado de turista hacia la RFA ${ }^{47}$. El IEE trató de depositar la responsabilidad de la ilegalidad en la concesión de visados de trabajo por los consulados alemanes en España más que en los visados de turista. En 1963, el Secretario General de la Dirección General de Empleo, Vicente Borregón Ribes, consideraba "inadmisible" la utilización de "segundos caminos de la emigración". El responsable de la Comisión Alemana en Madrid, Friedrich Malsbender, señalaba que

\footnotetext{
$44 \quad$ BA B119/3064 Resumen de las conversaciones...en Madrid 7 y 8. 09.1961...

Schönwälder (2003), p. 132 y ss., Herbert (2001).

Ministerio de Trabajo (1965), p. 9. IEE (1961): Ministerio de Trabajo (1966a): (1966b) (1966c).
}

BA B119/3064 Resumen de las conversaciones...en Madrid 7 y 8. 09.1961... 
según la legislación alemana, el acuerdo entre ambos países no excluía que los trabajadores españoles que así lo considerasen utilizasen el visado para entrar en la RFA. Si el Subdirector General de Empleo español "lamentaba" también que saliesen trabajadores "de forma clandestina como turistas", Malsbender reconocía abiertamente que estos "emigrantes-turistas" viajaban incluso en los mismos trenes y junto a los contingentes de la emigración oficial, que salían desde España. Era evidente que esta situación era también conocida y tolerada por las autoridades españolas y que las esperas, trabas y trámites burocráticos, que la propia vía oficial conllevaba, jugaban un importante papel en la elección de un camino al margen.

Estas salidas, fuera del marco de la contratación asistida, no solamente estuvieron condicionadas por las esperas burocráticas de la vía oficial, sino también por la mayor confianza en las redes de familiares y amigos desplazados frente a la vía oficial. En 1962, doscientos trabajadores procedentes de Gijón habían recibido información sobre sus contratos en empresas de la construcción en la RFA en el marco oficial de la emigración asistida. Al llegar, fueron integrados en la plantilla de una fábrica de chocolates. Casos similares en Madrid y Toledo causaron reticencias ante la vía oficial en los primeros años, en comparación con las garantías de información y de recursos que ofrecía la red de relaciones ${ }^{48}$. Además, comenzaron a establecerse en los primeros años actividades paralelas de gestión de contrataciones y de desplazamiento en manos de mediadores de empresas alemanas. En los primeros años y ante la creciente demanda de trabajo en la RFA, algunas autoridades provinciales actuaron de forma autónoma y llegaron a gestionar contratos con empresas alemanas al margen del IEE y de la Comisión Alemana ${ }^{49}$. La presencia de mediadores de empresas alemanas en Orense, hacia 1963, para contratar mujeres, y la actividad de un agente privado de la empresa Howaldt-Werke de Hamburgo, en 1961, en Barcelona para gestionar contratos y permisos de trabajo, mostraban la existencia de instituciones informales asociadas a las empresas alemanas, al margen de la "vía oficial" y de la red de relaciones personales. Si en 1960 la Comisión Alemana informaba de la presencia de representantes de empresarios que buscaban trabajadores en España directamente para agilizar trámites, en 1968, el propio Bundesanstalt für Arbeit reconocía en el informe anual sobre las oficinas federales, que los empresarios del metal de Hessen estaban llevando a cabo la contratación de trabajadores extranjeros por sí mismos, sin utilizar la gestión de estas oficinas federales ${ }^{50}$.

48 BA B/119/ 3352 Acta de la reunión 27.11.1962. BA B/119/ 3352 Acta de la reunión 27.03.196. Archivo de Caritasverband (ADCV) 380.22.048. Sozialdienst für Spanier...19-30.11.1967.

49 Sobre las actividades del delegado provincial del IEE de Castellón contratando al margen del IEE y de la Comisión Alemana BA B/119/ 3352 Acta de la reunión...27.11. 1962.

50 BA B/119/ 3069 Anwerbung und Vermittlung ...05.05.1960. B/119/ 3352 Acta de la reunión ...27.03.1963. B/119/ 3018 Landesarbeitsamt Hessen. Erfahrungsbericht...1968. 


\section{CUADRO 1}

EVOLUCIÓN COMPARATIVA DEL PORCENTAJE DE EMIGRACIÓN LABORAL CONTROLADA POR LAS COMISIONES ALEMANAS EN LOS DIFERENTES PAÍSES DE ORIGEN DE LA EMIGRACION

(emigración oficial o asistida) 1960-1973

\begin{tabular}{lrrrrrrrrrrrrrrr}
\hline & 1960 & 1961 & 1962 & 1963 & 1964 & 1965 & 1966 & 1967 & 1968 & 1969 & 1970 & 1971 & 1972 & 1973 & Prom \\
\hline Italia & 66,0 & 64,6 & 46,4 & 23,6 & 18,7 & 13,0 & 8,1 & 6,8 & 8,0 & 7,5 & 4,4 & 2,7 & 1,4 & 20,9 & \\
España* $^{38,0}$ & 53,0 & 66,0 & 68,2 & 68,1 & 62,2 & 68,5 & 41,8 & 72,6 & 83,7 & 83,0 & 78,5 & 78,4 & 89,6 & 68,0 \\
Grecia & 35,3 & 57,8 & 67,2 & 70,0 & 62,4 & 53,8 & 67,7 & 25,4 & 65,2 & 78,7 & 77,8 & 72,2 & 67,3 & 52,0 & 60,9 \\
Turquía & 17,0 & 72,2 & 84,0 & 87,3 & 76,2 & 74,8 & 48,8 & 66,5 & 80,8 & 77,4 & 64,9 & 86,0 & 86,0 & 70,9 \\
Portugal & & & & 46,2 & 73,8 & 79,9 & 46,3 & 69,9 & 86,0 & 90,2 & 86,3 & 87,5 & 95,7 & 76,2 \\
\hline
\end{tabular}

* Comparación del \% de emigrantes que llegan con la gestión del IEE y de la Comisión Alemana con los ofrecidos por el BAVAV/BAA.

Fuente: BAA (1974)

Los flujos de emigración de los distintos países que llegaban a la RFA mantuvieron cifras al margen del control y mostraron, en este sentido, una dinámica propia de difícil homogeneización para todos ellos. Italia pasó de un cierto control a comienzos de los 60 a establecer progresivamente una llegada al margen de la emigración asistida. Su pertenencia a la CEE fue operando en favor de una entrada libre en el mercado de trabajo alemán, quedando vinculada la emigración asistida a programas de cualificación. En el resto de países se incrementó el control de las salidas de trabajadores a la RFA desde mediados de los 60, con porcentajes más elevados en el caso de Turquía y de Portugal. A partir de entonces, las cifras de emigrantes contratados por medio de las vías oficiales se mantuvieron elevadas -con la única excepción de Grecia en 1973- hasta la desaparición de las Comisiones en los diferentes países.

El control de la emigración mostró, además, importantes diferencias de género. La segregación ocupacional convertía a hombres y mujeres en mano de obra diferenciada ${ }^{51}$. Si las decisiones de emigrar se tomaban en contexto de información similar, y si además, la decisión iba orientada a obtener una mayor utilidad de su renta a lo largo de su ciclo vital, no podemos obviar que el balance de la emigración asistida a la RFA fue desigual para hombres y mujeres. El flujo de llegadas fue un fenómeno mayoritariamente masculino, pero las llegadas de hombres y mujeres se produjeron de forma distinta (Anexo Gráfico 1) ${ }^{52}$. No se trataba solamente de una mayor

\footnotetext{
51 Sarasua y Gálvez (2003).

52 Más ampliamente sobre la mayor participación de las mujeres en las vías al margen de la emigración asistida en el caso de la RFA, Sanz Lafuente (2006), (en prensa a).
} 
presencia de las mujeres en fenómenos de reagrupación familiar al margen de relaciones laborales. Las mujeres vieron limitada su presencia en los contingentes oficiales de emigración laboral y se introdujeron también en esa misma emigración orientada al trabajo por medio de vías alternativas en mayor medida que los hombres.

Interesado en el peonaje industrial para empresas del textil y agroalimentarias, el BAVAV/BA trató de incrementar la presencia femenina en los contingentes de emigración asistida que salían de España y del resto de países de origen de la emigración ${ }^{53}$. La consolidación de un salario familiar masculino en la RFA, en alza durante este periodo, estuvo acompañado por un descenso de la participación de las mujeres casadas alemanas en el trabajo de peonaje industrial desde mediados de los cincuenta y por una ralentización en sus cifras de ocupación ${ }^{54}$. Paralelamente, la salida de la industria generó una movilidad de las mujeres alemanas hacia el sector terciario. Desde comienzos de los setenta avanzaron también formas de trabajo a tiempo parcial destinadas a mujeres casadas, con las que los ingresos femeninos se convertían en "complemento" del salario familiar masculino ${ }^{55}$. La amplia demanda de trabajo femenino emigrante destinado al peonaje industrial se vio reflejada incluso en la legislación de inmigración alemana de 1965, que restringía el segundo camino para los peones masculinos hacia la RFA, pero no para las mujeres y para los trabajadores cualificados ${ }^{56}$.

El flujo de emigración española a la RFA tuvo un claro componente masculino (71\%). En primer lugar, la división sexual del trabajo llevaba en mayor medida a los hombres casados que a las mujeres casadas a la emigración. También la existencia de proyectos migratorios de las familias a corto plazo tuvo su influencia en la composición por sexos. En el marco de un proceso de decisión familiar la opción fue, en ocasiones, la de la emigración de uno de los cónyuges y este hecho redujo la presencia femenina. En la encuesta de la Oficina Federal de Trabajo, el 30\% de los hombres casados españoles se encontraba separado de la familia en la RFA a finales de los 60 y en 1972 estos eran el 37\%. La legislación sobre reagrupación familiar hay que tenerla también en cuenta. Si la legislación alemana sobre extranjeros, en 1965, intentaba limitar la reagrupación familiar al poder solicitarla después de tres años de ocupación y de disponer de vivienda, estas limitaciones contaron con prácticas sociales diversas y numerosas discusiones entre los ministerios implicados ${ }^{57}$. Finalmente, una gestión oficial orientada a la emigración laboral y a la tramitación de contratos dejaba en gran medida fuera a mujeres e hijos en busca de la simple reagrupación familiar.

Otro aspecto a tener en cuenta es la diferente gestión de la emigración de hombres y mujeres por parte del IEE. La emigración asistida tenía una clara orientación

\footnotetext{
Mattes (2005).

Zimmermann (1985), p. 49 y ss.

Eckart (1986), pp. 183-249 y Kucera (2001), p. 103.

Mattes (2005), pp.137-158.

Schönwälder (2003), pp. 132 y ss. Herbert (2001).
} 


\section{CUADRO 2}

DIFERENCIAS EN EL FLUJO MIGRATORIO ACUMULADO Y ASISTIDO Y CIFRAS DE OCUPACIÓN DE HOMBRES Y MUJERES EN LA RFA 1960-1973

\begin{tabular}{lrrr}
\hline & Total & Hombres & Mujeres \\
\hline A. Flujo migratorio acumulado 1960-1973 & 749.352 & 532.362 & 216.990 \\
\% sobre flujo acumulado & 100 & 71,0 & 29,0 \\
B. Llegadas asistidas acumuladas 1960-1973 & 408.811 & 325.094 & 83.717 \\
\% sobre las llegadas asistidas & 100 & 79,5 & 20,5 \\
\% de B sobre A & 54,50 & 61,00 & 38,50 \\
C. Ocupados oficialmente* en la RFA 1962-1973 & 1.824 .155 & 1.266 .529 & 557.626 \\
(cifras anuales acumuladas) & & & \\
\% sobre la ocupación total española & 100 & 69,40 & 30,60 \\
\hline
\end{tabular}

* Se trata de cifras oficiales de contratación, que no recogen otras actividades laborales como las desarrolladas por las mujeres en el servicio doméstico. Sanz Lafuente (2006).

Fuente: Ver gráfico 1 y BAA (1974).

laboral tanto para hombres como para mujeres, pero mostraba un claro componente masculino en cuanto a su volumen. Si la emigración era un instrumento del 'desarrollismo' y un mecanismo para mejorar el mercado de trabajo interior, la opción de la emigración no se observaba por igual para hombres y mujeres ${ }^{58}$. La comparación de los flujos migratorios de hombres y mujeres a la RFA con las cifras de contratación oficial es una buena vía para demostrar las amplias diferencias existentes en la gestión oficial de la emigración masculina y femenina y la mayor presencia de las mujeres en los caminos al margen de esa gestión oficial ${ }^{59}$. Mientras que la emigración asistida masculina representó un 61\% del flujo de la emigración de los hombres hacia la RFA, la contratación asistida de las mujeres solamente representaría un 38\% del total de las españolas que llegaron ${ }^{60}$.

La canalización de ofertas de trabajo se restringió por parte del IEE en el caso de las mujeres, utilizando el argumento que asociaba en exclusiva a la mujer con en el trabajo reproductor -atención al hogar, cuidado de hijos y de dependientes- y la excluía de la emigración laboral ${ }^{61}$. El propio Ministro de Trabajo, Jesús Romeo

\footnotetext{
58 Fernández Vicente (2006), Fernández Asperilla (1998), Sanz Díaz (2004).

$59 \quad$ Zlotnik (2003).

60 ADCV 380.22.048. Sozialdienst für Spanier. Bericht ...1961.

61 Molinero (1998), pp. 97-117.
} 
Gorría, señalaba en el acta de la reunión del Consejo del IEE “la aplicación de determinadas medidas para evitar la emigración de mujeres menores de 21 años que suponía un evidente riesgo moral y espiritual"62. Junto a estos argumentos explícitos basados en el paternalismo, el control y la restricción del trabajo femenino durante el Franquismo, el crecimiento económico iba a demandar también fuerza de trabajo de las mujeres en el mercado de trabajo interior y además, en un contexto de amplia emigración exterior masculina de carácter rotatorio ${ }^{63}$. Como señala Lina Gálvez, las tasas de actividad registradas son las más bajas en comparación con otros países pero se incrementaron desde $1950(15,8)-1960(20,1), 1969(29,2)$ - hasta $1979(32,6)^{64}$. El propio Plan de Desarrollo de 1964 preveía un incremento general de la ocupación de las mujeres ${ }^{65}$. El tradicional subregistro de la actividad femenina, sobre todo en la ocupación agraria mayoritaria hasta los 60 -actividad de la mujer jornalera y de la mujer del pequeño propietario-, se limitó en el entorno urbano del desarrollismo, de ahí también, el incremento de las cifras de ocupación registrada ${ }^{66}$. En este sentido, y en relación con el trabajo de las mujeres casadas, Cristina Borderías señala cómo la Ley de Derechos Políticos, Profesionales y de Trabajo de la mujer en 1961 seguía manteniendo la previa autorización del marido para desarrollar actividades laborales pero reducía limitaciones anteriores del Fuero del Trabajo (1938) para la entrada en el mercado laboral ${ }^{67}$. Sin duda, los bajos salarios familiares masculinos, también estimularon, tanto el pluriempleo masculino, como la búsqueda de actividades laborales de mujeres casadas, especialmente en familias de bajos ingresos asentadas ahora en un entorno urbano, en el que el salario se convertía en eje de los ingresos familiares ${ }^{68}$.

En el desarrollismo convivieron acomodaciones legislativas tendentes a la "liberalización" del trabajo femenino como la ley del 61 y el decreto para su aplicación de 1962, medidas restrictivas con el trabajo de mujeres casadas como la autorización del

62 AMT. Acta de la reunión del Consejo del IEE celebrada el día 16 de enero de 1966. (sin catalogar).

63 ADCV 380.22.048. Sozialdienst für Spanier. Bericht von K. Gerhardy zur Auswanderung der spanischen Mädchen und Frauen in die deutsche Bundesrepublik, 1961. "El Estado está básicamente contra la emigración de las muchachas a Alemania, y esto es por que según su modo de ver no existe la misma necesidad de trabajo para ellas que para los hombres, ya que estas podrían encontrar una ocupación en España".

64 Gálvez Muñoz (2006), p.836-837 y Gálvez y Fernández (2007), p.498.

65 Plan de desarrollo económico y social, Madrid, 1963. Años 1963 a 1967, Madrid, Imprenta del Boletín Oficial del Estado, p.53.

66 Ver también Carrasco (1997), pp. 117-124.

67 Borderías (1993), pp. 15-82. En la ley de 1961 se señalaba: “Sigue siendo norma programática del Estado español, anunciada por la Declaración segunda del Fuero del Trabajo, la de "liberar a la mujer casada del taller y de la fábrica" pero ni esta norma veda el acceso a la mujer a la multiplicidad -por lo demás creciente- de ocupaciones no manuales, ni en cuanto a las manuales puede ni debe conseguirse por normas discriminatorias y prohibitivas, que más perjuicios que beneficios causan, sino por la elevación general de las rentas del trabajo, reales y no nominales, del marido (...)". BOE $n^{\circ}$ 173, 24 de julio de 1961. En el periodo en el que se enmarcaba la ley la elevación de las rentas reales masculinas no se había producido. Vilar (2004).

Vilar (2004), Pérez-Fuentes Hernández (2004), p. 230 y 231. 
marido o el cobro de indemnizaciones si abandonaba el trabajo tras el matrimonio y también, una práctica social en la que la actividad femenina -en especial de las casadas- se vinculó a formas de contratación informal y a economías sumergidas como era el caso del servicio doméstico o de las tareas auxiliares de las industrias, que a veces se desarrollaban a domicilio, como la industria del calzado, quedando así su labor al margen de los registros oficiales de actividad ${ }^{69}$.

Esta doble acomodación entre el ejercicio de control y la relajación de la norma mediante la práctica social concreta, existieron igualmente dentro del control de la emigración femenina. Sobre la base de los datos empíricos existentes, la capacidad y el interés del IEE por controlar y limitar la emigración laboral femenina existió, se ejerció y condujo a una modificación las vías de acceso a la emigración de las mujeres frente a los hombres. No obstante, también hay que señalar que las mujeres emigrantes -y los hombres- que viajaron con el visado de turistas a la RFA tramitaron su pasaporte -directa o indirectamente- en los turbios caminos de la Dirección General de Seguridad. Finalmente, si atendemos a los resultados cuantitativos y comparamos los porcentajes de contratación oficial femenina de los países con los que la RFA llevó a cabo acuerdos, hay que señalar, que los datos correspondientes a las mujeres españolas, son similares a los que aparecen en el caso de Turquía, Portugal o Yugoslavia (alrededor del 20\%). Por encima de todos ellos se encontraría Grecia, en donde el $39 \%$ de la emigración asistida correspondería a las mujeres.

\section{Cualificación y control de la emigración: intereses, negociación bilateral y resultados comparativos}

Analizar los efectos reales del marco regulatorio sobre la emigración de profesionales cualificados ya ha constituido una fructífera vía de estudio de la emigración desde hace varios años ${ }^{70}$. El segundo objetivo de este artículo es estudiar el papel de las instituciones políticas en la composición de la población emigrante atendiendo a la cualificación. La presencia de trabajadores cualificados en los contingentes de la emigración oficial fue otro de los puntos conflictivos en la relación entre los funcionarios federales y los responsables del $\mathrm{IEE}^{71}$. En realidad, la demanda de cualificación ya había sido un ingrediente de las políticas migratorias antes de la Segunda Guerra Mundial y formó parte de las políticas económicas y, por extensión, también de las de inmigración y emigración durante los años del crecimiento posterior a la guerra.

\footnotetext{
69 Biblioni y Pons (2001), Pérez Pérez (2007), pp. 77-138.

70 Wolter (1997), Iredale (2001).

71 Sanz Díaz (2004).
} 
En la RFA, con la ley de extranjeros de 1965 se incrementaba un interés por la cualificación de los inmigrantes estableciendo limitaciones de entrada para los peones sin cualificación. Creció, así, la demanda de experiencia y/o formación en las negociaciones con los países de origen. La entrada del socialdemócrata Karl Schiller como ministro de economía de la Gran Coalición CDU-CSU-SPD desde 1971, hizo más patente esta preocupación por la cualificación en el reclutamiento de mano de obra extranjera y las comisiones incrementaron el número de estos contratos desde comienzos de los setenta, a la vez que llegaban a éstas más demandas de este tipo ${ }^{72}$. En el caso de España, uno de los aspectos que se han puesto de manifiesto al estudiar el mercado de trabajo del Franquismo ha sido "la penuria de la formación profesional pública" y el fuerte déficit de trabajadores cualificados ${ }^{73}$. El propio primer plan de desarrollo observaba una deficiencia en la formación del capital humano ${ }^{74}$. Partiendo de estos hechos, en los estudios sobre la emigración exterior se ha puesto de manifiesto el interés de la Dictadura por controlar las salidas en el caso de los emigrantes cualificados ${ }^{75}$.

El grueso de la emigración a la RFA en España, si tomamos como referencia las cifras de la emigración asistida entre 1960 y 1965, se encontraba en el proceso de desagrarización y entre los peones industriales ${ }^{76}$. Una vez en la RFA, estos se integraron en el peonaje industrial de la metalurgia, de la siderurgia y de otras industrias manufactureras, formando estas áreas el grueso de las cifras de ocupación durante todo el periodo $^{77}$. Detrás de la limitación de salidas desde el IEE en los contingentes de emigración en zonas industriales en España, que tenían una demanda de peonaje y de cualificación, y detrás de la amplia contratación de peones y de las crecientes demandas de trabajadores cualificados desde la RFA primaban las necesidades del mercado interior de ambos países y sus resultados estuvieron también sujetos a procesos de negociación bilateral. No obstante, no solamente la labor de esta negociación influyó en las salidas de emigrantes cualificados al exterior. En los informes sobre la gestión de emigración laboral entre 1964 y 1966, las autoridades federales señalaban otros motivos para explicar la falta de cualificación de los contingentes de la emigración asistida. El incremento en la demanda de cualificación en el mercado de trabajo interior en Grecia y España habría contribuido a reducir las demandas de emigración de los trabajadores cualificados en ambos países $^{78}$. La escasa presencia de profesionales

BAA (1971) p. 31.

Maluquer de Motes y Llonch (2005), p. 1162. Babiano (1995), p. 113.

Plan de desarrollo económico..., p. 144.

Fernández Asperilla (1998), Sanz Díaz (2004), Sanz Lafuente (en prensa a).

Tomando como referencia la emigración asistida a la RFA el 73,2\% de los emigrantes eran peones industriales y el 12,5\% agricultores. Ministerio de Trabajo (1966), p. 20.

Harms (1986), pp.49-68.

BAVAV (1965), p. 21, BAVAV (1966), p. 21-22, BAVAV (1967), p. 30. También en este mismo sentido, sobre los contingentes de mineros BA B/119/ 3013 Erfahrungsbericht...1969. 
de hostelería griegos o españoles en los contratos oficiales se relacionada en 1970 con el desarrollo del mercado de trabajo interior y lo mismo ocurría con las demandas de enfermeras para trabajar en la RFA, que no se cubrían.

Para analizar las reducidas cifras de emigrantes asistidos cualificados hay que considerar el menor potencial de cualificación existente en España a comienzos de los sesenta y la demanda existente de estos trabajadores en el desarrollismo ${ }^{79}$. Además hay que tener en cuenta qué sectores comprendía la cualificación de los trabajadores extranjeros llegados a la RFA por medio de la emigración asistida. En 1961, diversos oficios vinculados a la construcción, seguidos a gran distancia de especialistas del metal, constituían el mayor porcentaje de trabajadores cualificados extranjeros que llegaban con contrato oficial. A estos se sumaban los mineros en 1963. Entre 1966 y 1969 se ampliaban las categorías. A los albañiles y gremios vinculados a la construcción -carpinteros o cerrajeros- y a aquellos con experiencia en industria textil y metalúrgica se sumaban soldadores y electricistas ${ }^{80}$. Si nos situamos en 1970 el $60 \%$ de los trabajadores cualificados extranjeros, que llegaron de forma oficial eran albañiles, carpinteros, cerrajeros y mineros. A estos les seguía la confección textil, con un $9 \%$ - en su mayoría mujeres -, los trabajadores de torno y fresa, con un $5 \%$, y los electricistas y soldadores con un 3\% cada uno. Dada la menor presencia de los españoles en sectores como la construcción o la minería en la RFA, las cifras de cualificación en estos dos ámbitos se reducían considerablemente.

La cualificación por medio de un sistema de formación profesional era escasa en los países de origen de la emigración a la RFA y esta falta de formación reglada, hizo que la experiencia previa se considerase, junto a esa escasa formación profesional, como sinónimo de cualificación. Ante la ausencia de títulos acreditativos o frente a la escasa correlación con sus homólogos en la RFA, la Oficina Federal de Trabajo generó una serie de pruebas de conocimiento en los países de salida, que, sin embargo, se llevaban a cabo, como se recogía en 1970, "según las posibilidades" 81 . En el informe sobre la actividad de la Comisión Alemana en España se señalaba que existían cuatro vías posibles para probar los conocimientos: los certificados de formación profesional existentes, que la mayor parte de los trabajadores no poseía, la utilización de clasificaciones profesionales en España y de tests enviados por las empresas junto a otras pruebas elaboradas por la propia Comisión en colaboración, en ocasiones, con los representantes laborales de la emigración a Francia o Suiza y finalmente, la información suministrada por los propios trabajadores. Esta práctica derivó en

79 Babiano (1995), Soto Carmona (2003).

80 BAVAV (1964), p. 13 y 14, BAVAV (1967), p. 30. BAVAV (1969), p. 32 y 33. BAA (1970), p. 31-32.

81 Solamente un certificado de primera categoría era considerado en 1973 homologable a un trabajador especializado en la RFA por parte del Director de la Comisión Alemana. BA B119/ 4691 Schreiben des Deutschen Kommission... 8.3.1972. BAA (1971). 
una falta de información sobre estos conocimientos profesionales, de manera que el mero reconocimiento de piezas y símbolos dibujados en un papel o un test podían servir para confirmar una determinada cualificación profesional ${ }^{82}$.

Junto a la evolución de la demanda en el mercado de trabajo y a la integración sectorial de los trabajadores españoles en el mercado de la RFA, la actividad del IEE y de la Comisión Alemana en el control de la composición de los flujos también es un aspecto a tener en cuenta. El informe de la Comisión Alemana de 1960 señalaba cómo tras unas pocas semanas reclutando personal cualificado habían comenzado una "oposición, que procedía de los círculos empresariales (...). También entre las autoridades se percibía esa tendencia, de que para una colocación en la RFA solamente deberían entrar en consideración los parados"83. Las dificultades para introducir al trabajador cualificado en las salidas hacia la RFA eran subrayadas reiteradamente en los informes de la Comisión Alemana en Madrid ${ }^{84}$. Las autoridades del IEE en España rechazaron las solicitudes de contratación de trabajadores cualificados del metal en empresas alemanas por cuestiones relacionadas con el propio mercado laboral interior, al subrayar que estos trabajadores "eran escasos" 85 .

En 1969 se remitían quejas al agregado laboral español desde la presidencia del BAVAV, subrayando las dificultades para contratar trabajadores cualificados en España y en 1970, el informe interno anual de la Comisión Alemana en Madrid señalaba que el IEE no establecía contingentes de salidas para los trabajadores cualificados e impedía la utilización de la prensa y de la radio a la Comisión para "conseguir mano de obra cualificada". En el mismo informe se señalaba que existía la sospecha, de que el IEE no buscaba la emigración desde zonas como Asturias, Vizcaya, Guipúzcoa, Álava y Barcelona por razones relacionadas con la demanda de mano de obra en estas zonas y que el IEE había excluido también a las regiones mineras para la contratación. Si en algunas zonas había restricciones, en otras no ocurría lo mismo: Andalucía, Galicia, Castilla, Extremadura y Murcia se consideraban en el mismo informe las zonas de expulsión de mano de obra en España ${ }^{86}$. Los representantes del BAVAV reconocían que el volumen de los reclutamientos se orientaba y dirigía según los intereses del Ministerio de Trabajo en España y que era éste el que fijaba "en cada caso la provincia donde ha de efectuarse el reclutamiento" ${ }^{\prime 87}$. De esta forma se trataba de orientar las demandas hacia determinadas zonas geográficas restringiendo otras.

\footnotetext{
82 BA B/119/ 4691 Schreiben des Deutschen Kommission... 8.3.1972.

83 BA B/119/3069 Anwerbung und Vermittlung ...12.05.1960.

84 BA B/119/ 3064. Anwerbung und Vermittlung ...1960. BA B/119/ 3352 Acta de la reunión...27. 11.1962. También BAVAV (1963), p. 12.

85 BA B/119/ 3065. Anwerbung und Vermittlung ...1962.

86 BA B119/ 3067B2 Carta de la presidencia del BAVAV al agregado laboral español en Bonn, Sr. Sorribes, 29.06.1969. B /119/3016. Deutsche Kommission in Spanien. Erfahrungsbericht 1970....

87 BA B 119/ 3352b1 Resumen de la reunión...8 de febrero de 1962, 14 de febrero de 1962. BA B/119/3940 Carta de la Comisión Alemana al Director General del IEE, 25.10.73.
} 
Las relaciones entre la Comisión Alemana y el IEE muestran la existencia de continuos procesos de negociación alrededor de intereses divergentes de ambos países en lo referente a la emigración de personal cualificado. En este proceso, la Comisión Alemana trató de utilizar la capacidad de actuación de los niveles de decisión a escala provincial frente al IEE. Con el fin de salvar ese control, la Comisión Alemana intentaba intensificar contactos con las delegaciones provinciales y sindicatos verticales a escala regional en 1970 buscando obtener mejores resultados en la contratación de mujeres y de trabajadores cualificados ${ }^{88}$. En otras ocasiones, los funcionarios federales vincularon las demandas de peones sin cualificación, en las que el IEE estaba especialmente interesado, a la presencia de especialistas, en los contingentes de trabajadores españoles que salían hacia la RFA. Günter Steinbacher, director de las Comisión Alemana, se oponía a la limitación de salidas de mujeres y de trabajadores cualificados por parte del IEE. A esto añadía: "que si se producía una limitación que él personalmente no saludaba en el caso de mujeres y de trabajadores cualificados, la totalidad de las demandas nominales disminuirían, sin que se pudiera contar con un incremento de la llegada de no nominales" ${ }^{\prime 89}$. En 1971, Steinbacher, se dirigía al Director General del IEE enviando una lista con más de quinientos puestos de trabajo para especialistas en la RFA, subrayando que hasta ese momento "no había habido posibilidades de contratación" de estas ofertas en España. Los funcionarios federales solicitaban entre otras muchas áreas, 120 albañiles, 22 torneros, 25 encofradores, 60 ajustadores mecánicos, 46 ebanistas y 19 especialistas en construcción naval. Estas demandas de trabajadores cualificados se asociaban poco después otras para peones -Hilfsarbeiter- en la empresa Mercedes-Benz. En este sentido se señalaba que "el incremento experimentado en la contratación de especialistas ha movido a empresas alemanas importantes a enviar también un mayor número de ofertas de peonaje $\mathrm{e}^{\prime \prime 90}$.

Los procesos de negociación estuvieron presentes en el incremento de trabajadores cualificados en los años 1971 y 1972 (Cuadro 3). Este incremento leve en los porcentajes de emigrantes cualificados que salían de España por medio de la vía oficial se produjo, durante esos dos años, en medio de una mayor presión de la Comisión Alemana y del avance de la competencia que representaban Yugoslavia y Turquía en la emigración laboral a éste país. Además, la organización del Servicio de Emigración Cualificada, recogido por la nueva la Ley de Emigración de 21 de julio de 1971, se apoyaba en la idea de una formación en el exterior de los trabajadores, en su necesaria inserción en áreas más cualificadas y en el interés por su pronto retorno. Detrás se encontraba, también, la búsqueda de financiación por parte del IEE así como la ampliación de su actividad de gestión burocrática, a través de sus relaciones con sectores oficiales y privados vinculados a la formación profesional en Francia, Suiza o la RFA. 
Emigrantes españoles y empresarios alemanes actuaron también en este marco restrictivo generando instituciones informales de emigración. En 1962, la respuesta de algunos trabajadores del metal a las trabas oficiales fue inscribirse como "peones" para ser aceptados o utilizar otras vías no oficiales ${ }^{91}$. No solamente los bajos salarios sino también la reducción de las diferencias salariales entre trabajadores cualificados y no cualificados en España pudieron estimular las salidas de los primeros a comienzos de los $60^{92}$. Con fechas posteriores, continuó la presencia de trabajadores cualificados en la emigración no oficial. En 1970, un representante de la liga de armadores alemanes establecía contactos con representantes de Marina Mercante, con representantes del sindicalismo vertical y con escuelas de formación en Galicia, con el fin de contratar marinos profesionales en Hamburgo. Unos cuarenta fueron contratados de forma oficial con la participación de la Comisión Alemana y del IEE. Ante la difusión de esta información algunos marinos profesionales viajaron a la RFA sin la mediación de la Comisión y del IEE. Por su parte, el representante de los armadores alemanes estableció contratos posteriormente sin atender a la mediación oficial con el fin de agilizar esta labor in situ ${ }^{93}$.

Dejando a un lado las cifras para Italia, escasamente representativas, dado que la emigración discurrió mayoritariamente por cauces no oficiales como miembro de la CEE, en términos generales, Grecia y España fueron los países que suministraron un promedio menor de trabajadores cualificados en los contingentes de la emigración asistida. Las elevadas cifras de Italia tenían además otra explicación, ya que era habitual que los peones utilizasen cada vez menos la vía oficial de contratación aprovechando el marco político de libre circulación, mientras que los cursos de formación profesional de la Comunidad Europea para aprendices - metal, construcción y hosteleríase canalizaban por medio de la Comisión Alemana en Italia. Turquía y Yugoslavia, se convirtieron en la principal cantera de la cualificación en la emigración asistida.

En ocasiones, las restricciones del IEE se combinaron con la colaboración basada en programas de formación. Ya en 1965, el director del IEE, Álvaro Rengifo Calderón, señalaba a representantes del Ministerio de Trabajo Federal que: "España necesitaba a sus trabajadores cualificados en un volumen considerable para su propia economía y que por ello solamente podía suministrar unos pocos proporcionalmente ${ }^{\prime 94}$. No obstante, Rengifo Calderón subrayaba que dada la necesidad de trabajadores cualificados en la RFA sería interesante llevar a cabo programas de formación de trabajadores no cualificados en España con la participación financiera del BAVAV/BA. Los intentos en este sentido, habían existido a comienzos de los sesenta y eran considerados por esas

BAVAV (1962), p. 13.

Vilar (2004), pp. 81-126.

BA B119/ Deutsche Kommission in Spanien. Erfahrungsbericht 1970.

BA B119/ 4547 Anwerbung und Vermittlung...April 1965. 


\section{CUADRO 3}

EVOLUCIÓN DEL PORCENTAJE DE TRABAJADORES CUALIFICADOS POR PAÍSES RESPECTO AL CONTINGENTE ANUAL DE EMIGRACIÓN ASISTIDA GESTIONADO POR LAS COMISIONES ALEMANAS EN CADA PAÍS 1961-1973

\begin{tabular}{lrrrrrrrrrrrrrrrr}
\hline & 1961 & 1962 & 1963 & 1964 & 1965 & 1966 & 1967 & 1968 & 1969 & 1970 & 1971 & 1972 & 1973 & Prom \\
\hline Italia & 20,9 & 19,6 & 14,1 & 20,4 & 36,9 & 44,5 & 39,2 & 24,2 & 27,1 & 29,9 & 36,1 & 45,7 & 19,4 & 29,1 \\
España & 5,7 & 12,4 & 8,9 & 5,5 & 5,6 & 5,7 & 7,0 & 6,7 & 3,5 & 4,1 & 10,9 & 19,2 & 15,5 & 8,5 \\
Grecia & 10,0 & 14,8 & 11,2 & 7,8 & 8,7 & 15,9 & 8,0 & 4,7 & 2,4 & 5,2 & 10,5 & 13,6 & 10,1 & 9,5 \\
Turquía & 38,3 & 46,8 & 18,1 & 16,9 & 34,8 & 31,2 & 32,8 & 26,4 & 28,2 & 34,0 & 46,3 & 30,3 & 29,7 & 31,8 \\
Portugal & & & & 11,3 & 17,0 & 11,5 & 16,1 & 10,3 & 13,1 & 14,9 & 23,0 & 31,0 & 33,1 & 18,1 \\
Yugoslavia & & & & & & & & & 18,0 & 27,5 & 30,1 & 36,0 & 36,4 & 29,6 \\
Túnez & & & & & & & & & & 33,9 & 34,5 & 42,5 & 9,2 & 30,0 \\
Marruecos & & & & & & & & & & & & 34,2 & 32,7 & 33,5 \\
\hline Promedio & 18,7 & 23,4 & 13,1 & 12,4 & 20,6 & 21,7 & 20,6 & 14,4 & 15,4 & 21,3 & 27,3 & 31,5 & 23,2 & 22,0 \\
\hline
\end{tabular}

Fuente: BAVAV, BAA (1962-1973)

fechas por las autoridades alemanas escasamente fructíferos en la práctica. A comienzos de los setenta se intensificaban las medidas relacionadas con la capacitación de los emigrantes y se ponían en marcha medidas de formación profesional asociadas a contratos en la RFA, con la participación de organizaciones de empresarios alemanes, del Ministerio Federal de Trabajo y de representantes oficiales del país de salida.

En el caso de España, las entidades encargadas de la gestión fueron la Dirección general del IEE y la de Promoción Social ${ }^{95}$. La Comisión Alemana intensificó sus relaciones con Promoción Profesional Obrera (PPO) con el fin de obtener trabajadores cualificados. 3.700 personas formadas en sus países de origen salían para trabajar en la RFA en 1971. La mayoría se formaban en el área del metal y procedían de Yugoslavia y de Turquía. Solamente 10 trabajadores procedían de España. En 1972 ascendían a tan solo 41 personas y en 1973 a $154^{96}$. La situación del mercado interior para estos grupos cualificados, el escaso interés ante periodos de formación en un contexto de pleno empleo y de una entrada en la vida laboral en edades más tempranas, así como la escasa actividad oficial de fomento en la capacitación profe- 
CUADRO 4

NIVEL PROFESIONAL DE LOS TRABAJADORES EXTRANJEROS EN LA RFA

(Promedio de \% en 1968/1972)

\begin{tabular}{|c|c|c|c|c|c|c|c|c|}
\hline & \multicolumn{2}{|c|}{ Especialista } & \multicolumn{2}{|c|}{$\begin{array}{c}\text { Peón } \\
\text { especializado }\end{array}$} & \multicolumn{2}{|c|}{ Peón } & \multicolumn{2}{|c|}{ Otros } \\
\hline & $\mathbf{H}$ & M & $\mathbf{H}$ & $\mathbf{M}$ & $\mathbf{H}$ & $\mathbf{M}$ & $\mathbf{H}$ & M \\
\hline Italia & 12,5 & & 41,5 & 41,5 & 42,5 & 53 & 3,5 & 5,5 \\
\hline Grecia & 7,5 & & 55,5 & 44,5 & 34 & 52,5 & 3 & 3 \\
\hline España & 14 & & 46,5 & 39 & 36 & 53,5 & 3,5 & 7,5 \\
\hline Portugal & 12 & & 46,5 & 39 & 39,5 & 54,5 & 2 & 6,5 \\
\hline Turquía & 16 & & 42,5 & 38,5 & 39 & 56 & 2,5 & 5,5 \\
\hline Yugoslavia & 48 & & 31 & 37 & 16,5 & 47,5 & 4,5 & 15,5 \\
\hline
\end{tabular}

Fuente: BAA (1969), (1973) ${ }^{97}$

sional para la RFA, constituían la base de una participación reducida de los trabajadores españoles en estos programas. Las cifras de trabajadores procedentes de España por medio de este sistema siguieron siendo las más bajas en los años siguientes.

Ambas entidades oficiales -IEE y Comisión Alemana- combinaron la negociación de salidas de trabajadores sobre la base de las demandas del mercado laboral interior, condicionando la presencia de cualificados en los contingentes oficiales. Fuera de esta emigración asistida se había desarrollado, sin embargo, una emigración paralela a la RFA en la que tuvieron cabida los trabajadores cualificados españoles. No disponemos de series de cualificación con los datos de llegada de los flujos a la RFA. No obstante, en las dos investigaciones llevadas a cabo por la Oficina Federal de Trabajo en 1968 y 1972, un promedio del 14\% de los hombres españoles trabajaban como especialista en su empresa en la RFA y también había porcentajes elevados de peones especializados (Cuadro 4). Si bien el origen de la mayoría de los emigrantes -sector agrario y del peonaje industrial-, el nuevo idioma o la escasa presencia de títulos profesionales en el marco, además, de una emigración rotatoria centrada en el ahorro y el retorno, les alejaba del trabajo como especialistas y de una mayor promoción interna en la industria en la RFA, tampoco puede descartarse la presencia de fenómenos relacionados con la escasa adecuación entre la experiencia previa en un sector y el puesto de trabajo

97 Universo de la investigación del Ministerio de Trabajo Federal. 1968: 9.087 encuestas realizadas por oficinas de Trabajo Federales. 1972: 13.961 encuestas (ídem). 
desempeñado por los emigrantes en la RFA ${ }^{98}$. La conflictividad asociada al rechazo de contratos de aprendizaje en mujeres ocupadas en el textil y sus demandas de un mejor puesto de trabajo serían una expresión de esta falta de adecuación ${ }^{99}$. Además de la conflictividad, la respuesta de los trabajadores emigrantes españoles ante una limitada promoción dentro de la empresa fue la elevada fluctuación en la búsqueda de un mejor salario: un 54\% de los hombres encuestados por Caritasverband en 1967 y un $39 \%$ de las mujeres habían cambiado de empresa una vez instalados en la RFA ${ }^{100}$.

\section{Conclusiones}

La emigración laboral de trabajadores españoles a la RFA fue el resultado de un complejo proceso en el que se combinaron decisiones individuales, condiciones estructurales y una infraestructura burocrática orientada a la gestión y control de flujos migratorios, que en el marco de un ciclo económico expansivo, se basó en la liberalización controlada por parte de los dos Estados, en un acuerdo bilateral y en procesos de negociación. La comparación de las cifras procedentes de fuentes de información del IEE, en España, y del BAVAV / BAA, además de los datos de la Oficina Federal de Estadística, permiten aproximarnos con mayor fiabilidad a los resultados cuantitativos de la labor de control del sistema de Gastarbeiter en España. Alrededor de un 30\% de los trabajadores que llegaron a la RFA como emigración laboral entre 1960 y 1973 lo hicieron fuera de de los cauces oficiales. Estas cifras se elevan al 45\% si salimos de la información laboral y comparamos los contratos asistidos con los datos del flujo de emigración de la Oficina Federal de Estadística. En líneas generales, la gestión burocrática avanzó en el control de los flujos de emigración desde 1960 -el 38\% de los trabajadores que llegaron eran emigrantes asistidos- hasta su desaparición, en 1973 (89\%). La consideración de la legalidad e ilegalidad discurrió de forma distinta en la RFA, en donde los tres caminos de la emigración fueron considerados legales, con limitaciones como las establecidas en la ley de 1965 y en 1972, y con una férrea reducción coyuntural en las entradas durante la crisis económica de 1967. En España, la opción oficial discurrió entre la oposición a la emigración fuera del control oficial y su aceptación explícita, al reconocerse abiertamente la necesidad de la emigración para el desarrollismo. La gestión de flujos migratorios fue desigual en el caso de las mujeres y de hombres. Este hecho hizo a las mujeres más dependientes del capital social de las redes familiares y de amistad y del capital de insti-

\footnotetext{
$98 \quad$ Ver nota 73.

99 Sanz Díaz (en prensa), Sanz Lafuente (2006).

100 Sanz Lafuente (2006b), p. 475-487.
} 
tuciones informales -en especial de los mediadores de las empresas alemanas- para llevar cabo un proyecto migratorio laboral y la propia reagrupación familiar en la RFA. Si los hombres emigrados a la RFA por medio de la gestión del IEE y de la Comisión Alemana representaban el 61\% del flujo migratorio masculino desde España, estas cifras solamente fueron del $38 \%$ en el caso de las mujeres.

En lo referente a la participación de los trabajadores cualificados en la emigración, los datos existentes para Grecia y España muestran que en sus contingentes oficiales salieron las cifras más bajas de trabajadores cualificados de todos los países con los que la RFA estableció acuerdos de emigración. Unas cifras, que se incrementaron en los 70 en medio de procesos de negociación, de competencia entre países con acuerdos bilaterales de emigración y de una mayor demanda de las empresas, sustentada por una política de emigración alemana favorable. Las negociaciones sobre la composición de los contingentes discurrieron desde los inicios en medio de la consideración de las necesidades del mercado de trabajo interior de cada uno de los dos países y se vieron afectadas por esa misma evolución. En este contexto restrictivo, existieron también estrategias al margen utilizadas por los emigrantes, que omitieron su cualificación en los controles oficiales y utilizaron otras vías de salida y también, por las empresas alemanas, que generaron instituciones informales de mediadores en busca de trabajadores cualificados. Por un lado, el control del IEE no había sido total y trabajadores cualificados pudieron salir hacia la emigración laboral a la RFA. Por otro, y pese a que las autoridades federales alemanas buscaron la cualificación desde comienzos de los 60, el peón sin cualificación procedente del sur encontró una mayor integración en el mercado laboral industrial alemán ${ }^{101}$. Este mercado laboral con una elevada presencia de la producción en masa, demandó e introdujo a los trabajadores del sur de Europa en los niveles profesionales más bajos ${ }^{102}$. Pese a tener un menor porcentaje en el conjunto de la emigración, el papel de estos trabajadores cualificados fue, sin embargo, muy significativo y útil en el interior de la empresa en la RFA, al contribuir estos a gestionar procesos de trabajo y costes de transacción de los emigrantes menos cualificados procedentes de sus propios países.

\section{Fuentes}

Archivo del Ministerio de Trabajo (AMT)

Bundesarchiv Koblenz/ Archivo Federal de Coblenza (BA)

Archiv des Deutschen Caritasverbandes e.V / Archivo de la Federación de Caritas de Alemania en Friburgo (ADCV)

\footnotetext{
$101 \quad$ Young-Il (2003).

102 Ambrosius (1998), pp. 107-128, Abelshauser (2004), pp. 319 y ss.
} 


\section{Bibliografía}

ABELSHAUSER, Werner (2004): Deutsche Wirtschaftsgeschichte seit 1945, München, C. H. Beck.

ALONSO ANTOLIN, María Cruz (1983): La emigración gallega asistida a la República Federal de Alemania, Francia y Suiza, Madrid, Ministerio de Trabajo/IEE.

AMBROSIUS, Gerold (1998): “Wirtschaftlicher Strukturwandel und Technickentwicklung" en SCHILDT, Axel and SYWOTTECK, Arnold (eds.), Modernisierung im Wiederaufbau. Die Westdeutsche Gesellschaft der 50er Jahre, Bonn, Dietz, pp. 107128.

ANTOLIN, Pablo (1992): Labour market and international migrations flows: The case of Spain ( 1960-1988), Valencia, IVIE, Working Paper, 92-09.

BAA (1969): Ergebnisse der Representativuntersuchung von Herbst 1968, Nuremberg.

-(1973): Representatiountersuchung '72 über die Beschäftigung ausländischer Arbeitnehmer im Bundesgebiet und Ihre Fanilien-und Wohnverhätnisse, Nuremberg, 1973.

BAVAV (1962): Beschäftigung Anwerbung Vermittlung ausländischer Arbeitnehmer. Erfahrungsbericht 1961, Nuremberg, BAVAV. ( Idem 1963-1969).

BABIANO MORA, José (1995): Emigrantes, cronómetros y huelgas, Madrid, Siglo XXI.

BABIANO MORA, José y FERNÁNDEZ ASPERILLA, Ana (2002): El fenómeno de la irregularidad en la emigración española de los años sesenta, Madrid, Fundación $1^{\circ}$ de Mayo.

BAUER, Thomas ZIMMERMANN, Klaus (1996): “Gastarbeiter und Wirtschaftsentwicklung im Nachkriegsdeutschland", Jahrbuch für Wirtschaftsgeschichte, 2, pp. 74-108.

BETHLEHEM, Siegfried (1982): Heimatvertreibung, DDR-Flucht, Gastarbeiterzuwanderung. Wanderungsströme und Wanderungspolitik in der Bundesrepublik Deutschland, Stuttgart, Klett-Cotta.

BIBILONI, Andreu y PONS, Jerónia (2001): “La fuerza de trabajo en la industria del calzado de Mallorca 1900-1970". Comunicación presentada al VII Congreso de la Asociación de Historia Económica, sección: "Mujeres y hombres en los mercados de trabajo. La evolución histórica de los mecanismos de acceso y movilidad interna", septiembre, 2001.

BORDERIAS, Cristina (1993): “La división sexual del empleo y el trabajo: ¿Entre la tradición y la modernidad?", en BORDERIAS, Cristina (ed.), Entre líneas. Trabajo e identidad femenina en la España contemporánea, Barcelona: Icaria, pp.15-82.

BREITENBACH, Barbara von (1982): Italiener und Spanier als Arbeitnehmer in der Bundesrepublik Deutschland. Eine vergleichende Untersuchung zur europäischen Arbeitsmigration, Grünewald, Kaiser.

BRETTELL, Caroline B., HOLLIFIELD, James F. (2008) (eds.): Migration Theory. Talking across disciplines, New York/ London, Routledge. 
BUNDESANSTALT FÜR ARBEIT (BAA) (1970): Ausländische Arbeitnehmer. Beschäftigung, Anwerbung-Vermittlung-Erfahrungsbericht 1969, Nuremberg, BAVAV. (Idem 1971-1974).

CARDELUS, Jordi y PASCUAL, Angels (1979): Movimientos migratorios y organización social, Barcelona, Península.

CARRASCO, Cristina et alii (1997): Mujeres, trabajos y políticas sociales: una aproximación al caso español, Madrid, Ministerio de Trabajo y Asuntos Sociales/ Instituto de la Mujer.

CASTLES, Stephen KOSACK, Godula (1973): Immigrant Workers and Class Structure in Western Europe, London, Oxford University Press.

CORNELIUS, Wayne A., MARTIN Philip L., HOLLIFIELD, James F. (1994) (eds.): Controlling Immigration. A Global Perspective, Stanford, Stanford University Press.

DOHSE, Knuth (1985): Ausländische Arbeiter und bürgerlicher Staat. Genese und Funktion von staatlicher Ausländerpolitik und Ausländerrecht. Vom Kaiserreich bis zur Bundesrepublik Deutschland, Berlín, Express Edition.

DÜWELL, Frank (2006): "Irregular Migration: a Global, Historical and Economic perspective", en DÜWELL, Frank (ed.), Illegal Immigration in Europe. Beyond Control?, Houndmills/New York, Palgrave MacMillan.

ECKART, Christel (1986): “Halbtags durch das Wirtschaftswunder. Die Entwicklung der Teilzeitarbeit in den sechziger Jahren" en KRAMER, Heldgard et alii (ed.), Grenzen der Frauenlohnarbeit. Frauenstrategien in Lohn-und Hausarbeit seit der Jahhundertwende, Frankfurt am Main, pp. 183-249.

FERNÁNDEZ ASPERILLA, Ana (1998): “La emigración como exportación de mano de obra. El fenómeno migratorio a Europa durante el Franquismo", Historia Social, 30, pp. 63-81.

-(2006): Mineros, sirvientas y militantes. Medio siglo de emigración española a Bélgica, Madrid, CDEE.

FERNANDEZ VICENTE, María José (2004) : Émigrer sous Franco. Politiques publiques et stratégies individuelles dans l'émigration espagnole vers l'Argentine et vers la France (1945-1965), Lille Cedex, ANRT.

-(2006): "De calamidad nacional a baza del desarrollo. Las políticas migratorias del Régimen franquista (1939-1975)", Migraciones \& Exilios, 6, 2006.

GALVEZ MUÑOZ, Lina (2006): "Los mercados de trabajo en la España del siglo XX" en GONZALEZ ENCISO, A. y MATÉS BARCO, J.M. (coords.), Historia económica de España, Barcelona, Ariel, pp. 833-858.

GALVEZ MUÑOZ, Lina y FERNÁNDEZ PÉREZ, Paloma (2007): “Female Entrepreneurship in Spain during the Nineteenth and Twentieth Century's", Business History Review 81 (autumn 2007), pp. 495-515.

GARCÍA FERNÁNDEZ, Jesús (1965): La emigración exterior de España, Barcelona, Ariel. 
GARMENDIA, José Antonio (1981): “Emigración Española a Alemania, en GARMENDIA, José Antonio (ed.), La emigración española en la encrucijada. Marco general de la emigración de retorno, CIS, Madrid, pp. 245-286.

GARMENDIA, José Antonio (1970): Alemania: exilio del emigrante, Plaza\& Janés, Barcelona.

GOSS, Jon LINDQUIST, Bruce (1995): "Conceptualizing international labor migration: a structuration perspective", en International Migration Review, 29, pp. 317351.

GROSS, Dominique M. (2007): "Immigration Incentives and Policy in Switzerland" en ÖZDEN, Ç. y SCHIFF, M. (eds.), International Migration Economic Development and Policy, Washington, Palgrave Macmillan/ World Bank, pp. 183-214.

HARMS, Hans (1986): “La emigración española a Alemania”, Papers. Revista de Sociología, 27, pp. 49-68.

HATTON, Timothy J. y WILLIAMSON, Jeffrey G. (2005): Global Migration and the World Economy. Two Centuries of Policy and Performance, Cambridge, MIT.

—(2007): “ A Dual Policy Paradox: Why have Trade and Immigration Policies always differed in Labor-Scarce Economies?" en HATTON, Timothy J. O'ROURKE, Kevin H. TAYLOR, Alan M. (eds.), The new Comparative Economic History, Cambridge, MIT, pp. 217-240.

HERBERT, Ulrich (2001): Geschichte der Ausländerpolitik in Deutschland. Saisonarbeiter, Zwangsarbeiter, Gastarbeiter, Flüchtlinge, München, C.H. Beck.

HOLLIFIELD, James F. (1992): Immigrants, Markets and States. The political economy of postwar Europe, Cambridge, Harward University Press.

IEE (1960): Acuerdo entre el Estado español y la República Federal de Alemania sobre Migración, contratación y colocación de trabajadores españoles, Madrid, IEE.

-(1961): Apuntes sobre el problema laboral español en la actualidad, Madrid, IEE. (Redactado por Enrique Larroque).

-(1965a): Técnica y política de la emigración española, Madrid, Ministerio de Trabajo/IEE.

-(1965b): Informe sobre la coyuntura de la mano de obra en española en Europa en 1965, Madrid, Ministerio de Trabajo/IEE.

IREDALE, Robyn (2001): “The migration of professionals: Theories and Typologies", International Migration 39, pp. 7-24.

JOPPKE, Christian (1998): Challenge to nation-state: immigration in Western Europe and the United States, Oxford, Oxford University Press.

KARRAS, Georgios CHISWICK, Carmel U. (1999): “Macroeconomic Determinants of Migration: The case of Germany", International Migration 37, pp. 657-677.

KINDLEBERGER, Charles P. (1967): Europe's postwar growth: the role of labor supply, Harvard, Harvard University Press. 
KING, Russell RYBACZUK, Krysia (1993): "Southern Europe and the International Division of Labour: From Emigration to Immigration" en KING Russell (ed.), The New Geography of European Migration, London, pp. 175-206.

KUCERA, David (2001): Gender, Growth and Trade. The miracle economies of the postwar years, Routledge, London.

LEWIS W. Arthur (1954): "Economic development with unlimited supplies of labour", Manchester School of Economic and Social Studies, 22, pp. 139-191.

LIVI BACCI, Massimo (1972) (ed.): The Demographic and Social Pattern of Emigration from the Southern European Countries, Firenze, Departamento Statistico Matematico dell'Università di Firenze/ Comitato Italiano per lo Studio de Problemi della Popolazione.

KNORTZ, Heike (2008): Diplomatische Tauschgeschäfte. Gastarbeiter in der westdeutschen Diplomatie und Beschäftigung Politik 1953-1973, Köln/ Weimar/Wien, Böhlau.

KREIENBRINK, Axel (2004): Einwanderungsland Spanien. Migrationspolitik zwischen Europäisierung und nationalen Interessen, Frankfurt am Main, IKO.

MALUQUER DE MOTES, Jordi, LLONCH, M. (2005): “Trabajo y relaciones laborales" en CARRERAS, Albert, TAFUNELL, Xavier (coords.), Estadísticas Históricas de España, Bilbao, Fundación BBVA, pp. 1157-1245.

MASSEY, Douglas S. TAYLOR, J. Edward (2004) (ed.): International Migration. Prospects and Policies in a Global Market, Oxford, Oxford University Press.

MASSEY, Douglas, ARANGO, S. J., HUGO, G., KOUAOUCI, A., PELLERINO, A., TAYLOR, J.E. (1993): “Theories of international migration: A review and appraisal", Population and Development Review 19 (3), pp. 431-466.

-(2002) (eds.): Worlds in motion: understanding migration at the end of millennium, Oxford, Oxford Clarendon Press.

MATTES, Monika (2005): Gastarbeiterinnen in der Bundesrepublik, Frankfurt/ New York, Campus.

MERTINS, Günter (1984) (ed.): Untersuchungen zur spanischen Arbeitsmigration, Marburg. Geograph. Inst. d. Univ.

MESSINA, Anthony (2007): The Logics and Politics of Post-WWII Migration to Western Europe, Cambridge, Cambridge University Press.

MOLINERO, Carme (1998): "Mujer, franquismo, fascismo: La clausura forzada en un "mundo pequeño", Historia Social, n ${ }^{\circ}$ 30, pp. 97-117.

MINISTERIO DE TRABAJO (1965): La coyuntura de la mano de obra española en Europa, Madrid, Ministerio de Trabajo.

-(1966a): Emigración, balanza de pagos y expansión comercial, Madrid, Ministerio de Trabajo/ IEE. (Redactado por Álvaro Rengifo Calderón).

-(1966b): Emigración y Economía, Madrid, Ministerio de Trabajo /IEE. (Redactado por Álvaro Rengifo Calderón). 
-(1966c): Emigración y empresas privadas, Madrid, Ministerio de Trabajo/IEE. (Redactado por Álvaro Rengifo Calderón).

-(1966d): La emigración española a Alemania, Madrid, Ministerio de Trabajo-IEE. (Redactado por Álvaro Rengifo Calderón).

-(1966e): Informe sobre emigración 1966, Madrid, Ministerio de Trabajo/ IEE.

MINISTERIO DE TRABAJO Y SEGURIDAD SOCIAL (1986): Panorama de la emigración española a Europa, Madrid, Ministerio de Trabajo y Seguridad Social.

MONEY, Jeannette (1999): Fences and Neighbours: The Political Geography of Immigration Control, Ithaca, Cornell University Press.

NAVARRO LÓPEZ, Manuel (1981): “El contexto socioeconómico de la emigración continental española (1945-1975)” en GARMENDIA, José Antonio (ed.), La emigración española en la encrucijada. Marco general de la emigración de retorno, Madrid, CIS, pp. 15-40.

NICOLAU, Roser (2005): "Población, salud y actividad", en CARRERAS, Albert, TAFUNELL, Xavier (coords.), Estadísticas Históricas de España, Bilbao, Fundación BBVA, pp. 79-154.

NOVINSCAK, Karolina (2007): "Der jugoslawische "Gastarbeiter-Export" auf dem Sonderweg zwischen Kapitalismus und Sozialismus", en FLEGEL, Silke et alii (eds.), Wahl und Wagnis Migration, Berlín, Lit., pp. 141-161.

OECD (1975): The OECD and International Migration, Paris, OECD.

-(1978): Migration, growth and development, Paris, OECD.

PÉREZ DÍAZ, Victor (1972): Cambio tecnológico y procesos educativos en España, Madrid, Seminarios y Ediciones.

PÉREZ-FUENTES HERNANDEZ, Pilar (2004): “Los límites del modelo de male breadwinner family. Un ejercicio de historia comparada entre la primera y la segunda industrialización. Vizcaya 1900-1965" en Ídem "Ganadores de pan" y "amas de casa". Otra mirada sobre la industrialización vasca, Bilbao, Servicio Editorial de la Universidad del País Vasco, pp. 205-255.

PÉREZ PÉREZ, José Antonio (2007): “Trabajo doméstico y economías sumergidas en el gran Bilbao a lo largo del desarrollismo: un mundo invisible y femenino" en BABIANO, José (coord.), Del hogar a la huelga: trabajo, género y movimiento obrero durante el Franquismo, Madrid, Libros de La Catarata, pp. 77-138.

PIORE, Michael J. (1979): Birds of Passage: Migrant Labor in Industrial Societies, London, Cambridge University Press.

PUYOL ANTOLIN, Rafael (1979): Emigración y desigualdades regionales en España, Madrid, Emesa.

RODENAS CALATAYUD, Carmen (1994): Emigración y economía en España (19601990), Madrid.

RODRIGUEZ BARRIO, Ismael (2006): “La emigración española en el sector carbonífero belga", Migraciones E Exilios 7, diciembre, pp. 99-114. 
ROMANO-GARCÍA, Manuel (1995): “Die spanische Minderheit", en SCHMALZJACOBSEN, Cornelia et alii (eds.), Ethnische Minderheiten in der Bundesrepublik Deutschland. Ein Lexikon. München, Beck, pp. 468-481.

SÁNCHEZ LÓPEZ, Francisco (1969): Emigración española a Europa, Madrid, Confederación Española de Cajas de Ahorros.

SANZ DÍAZ, Carlos (2004): Clandestinos", "ilegales" y "espontáneos". La emigración ilegal de españoles a Alemania en el contexto de las relaciones hispano-alemanas, 19601973, Madrid, Comisión Española de Historia de las Relaciones Internacionales. -(2006): "La emigración española a Alemania" en FUNDACIÓN FRANCISCO LARGO CABALLERO-OBRA SOCIAL DE CAJA DUERO (2006) (ed.), De la España que emigra a la España que acoge, Salamanca, Obra Social Caja Duero, pp. 289-306.

—(en prensa a): “Un atajo al país del milagro económico. La emigración irregular de españoles a la República Federal de Alemania bajo el Franquismo".

-(en prensa $b)$ :"Mercados de trabajos, políticas migratorias y prácticas individuales en la emigración española a Alemania, 1955-1982" en DE LA TORRE, Joseba; SANZ LAFUENTE, Gloria (eds.), Migraciones y coyuntura económica del franquismo a la democracia.

SANZ LAFUENTE, Gloria (2006): “Mujeres españolas emigrantes y mercado laboral en Alemania, 1960-1975", MigracionesE Exilios, diciembre, pp. 27-50.

-(2006b): “Hombres y mujeres en el mercado de trabajo de la emigración: promoción laboral y rotación inter-empresarial de los emigrantes españoles en la RFA, 1960-1975", Revista Universitaria de Ciencias del Trabajo, 7, pp. 475-487.

-(en prensa a): "Género y emigración. Hombres y mujeres ante el mercado de trabajo de la emigración española a Alemania. 1960-1975" .

—(en prensa b): "Spanische Männer und Frauen zum deutschen Arbeitsmarkt, 19601973".

SARASUA, Carmen, GALVEZ, Lina (2003) (eds.): ¿Privilegios o eficiencia? Mujeres y hombres en los mercados de trabajo, Alicante, Universidad de Alicante.

SASSEN, Saskia (2001): ¿Perdiendo el control?: la soberanía en la era de la globalización, Barcelona, Bellaterra.

SCHÖNWÄLDER, Karen (2003): “Zukunftsblindheit oder Steuerungsversagen? Zur Ausländerpolitik der Bundesregierungen der 1960er und frühen 1970er Jahre", en OLTMER, Jochen (ed.), Migration steuern und verwalten. Deutschland vom späten 19. Jahrhundert bis zur Gegenwart, Osnabrück, V\&R, pp. 123- 144.

SILVESTRE RODRÍGUEZ, Javier (2000): “Aproximaciones teóricas a los movimientos migratorios contemporáneos: Un estado de la cuestión" en Historia Agraria, 21, pp. 157-194.

SONNENBERGER, Barbara (2003): “Verwaltete Arbeitskraft: die Anwerbung von "Gastarbeiterinnen" und "Gastarbeitern" durch dir Arbeitsverwaltung in den 
1950er und 1960er Jahren", en Oltmer, Jochen (ed.), Migration steuern und verwalten. Deutschland vom späten 19. Jahrhundert bis zur Gegenwart., Osnabrück: V\&R, pp. 145-174.

SOTO CARMONA, Álvaro (2003): El trabajo en España de la crisis del sistema gremial a la flexibilización, Madrid, Entrelíneas.

STARK, Oded (1993): La migración del trabajo, Madrid, Ministerio de Trabajo y Seguridad Social.

STEINERT, Johannes-Dieter (1995): Migration und Politik. Westdeutschland-EuropaÜbersee 1945-1961, Osnabrück, Secolo Verlag.

TAPINOS, George (1974): L'économie des migrations internationales, Fond. National des Sciences Politiques, Armand Colin, Paris.

VENTURINI, Alexandra (2004): Postwar Migration in Southern Europe, 1950-2000. An economic Analysis, Cambridge, Cambridge University Press.

VILAR RODRÍGUEZ, Margarita (2004): “La ruptura postbélica a través del comportamiento de los salarios industriales: nueva evidencia cuantitativa, 1908-1963", Revista de Historia Industrial 25, pp. 81-126.

VILAR, Juan Bautista VILAR, María José (1999): La emigración española a Europa en el siglo XX, Madrid, Arco Libros.

WOLTER, Achim (1997): "Qualifikationsspezifische Determinanten der Migration nach Deutschland“, Mitteilungen aus der Arbeitsmarkt-und Berufsforschung, Stuttgart, Kohlhammer, 3, pp. 657-662

YOUNG-IL, L. (2003): Ausländerbeschäftigung und technischer Fortschritt: Die Anwerbepolitik der Bundesrepublik im Vergleich mit der geschlossenen Arbeitsmarktpolitik Japans (1955-1973), Dissertation, Universität Bielefeld.

ZIMMERMANN, Klaus F. BAUER, Thomas (2002): The economics of migration. The Migration Decision and the Immigration Policy. Vol. I, Cheltenham/Northampton, Elgar Publishing Limited.

ZIMMERMANN, Klaus F. (ed.): How labor migrants fare, Berlin/Heidelberg, Springer. -(2007): Immigration policy and the labor market. The German experience and lessons from Europe, Berlín/ Heidelberg, Springer.

ZLOTNIK, Hania (2003): Global Dimensions of Female Migration, Washington, DC: Migration Policy Institute.

ZOLBERG, Aristide R. (1981): "International Migrations in Political Perspective", en KRITZ, M.; KEELY, C.; TOMASI, S. (eds.), Global Trends in Migration, Staten Island, Centre for Migration Studies, pp.15-51.

-(2006): A Nation by Design. Immigration Policy in the Fashioning of America, Cambridge, Harvard University Press. 


\section{APÉNDICE 1}

COMPARACIÓN NUMÉRICA DE FLUJOS DE EMIGRACIÓN ESPAÑOLA A RFA PROCEDENTES DE DIFERENTES FUENTES

\begin{tabular}{|c|c|c|c|c|c|}
\hline & $\begin{array}{l}\text { Emigrantes } \\
\text { laborales } \\
\text { asistidos con } \\
\text { contrato } \\
\text { oficial }(\mathrm{A})\end{array}$ & $\begin{array}{l}\text { Emigrantes } \\
\text { estimados }\end{array}$ & $\begin{array}{l}\text { Emigrantes } \\
\text { laborales } \\
\text { asistidos y no } \\
\text { asistidos (B) }\end{array}$ & Diferencia & $\begin{array}{c}\text { Flujo } \\
\text { migratorio } \\
\text { (C) }\end{array}$ \\
\hline Fuente & BAVAV/BAA/ IEE & IEE & BAVAV/BAA & $A-B$ & $\begin{array}{c}\text { Oficina } \\
\text { Federal de } \\
\text { Estadística }\end{array}$ \\
\hline 1959 & & 1.885 & 1.885 & & \\
\hline 1960 & 10.175 & 10.011 & 26.703 & -16.528 & 32.220 \\
\hline 1961 & 27.099 & 56.192 & 51.117 & -24.018 & 55.079 \\
\hline 1962 & 36.287 & 42.517 & 54.893 & -18.606 & 62.561 \\
\hline 1963 & 35.265 & 36.604 & 51.715 & -16.450 & 62.134 \\
\hline 1964 & 44.880 & 47.399 & 65.872 & -20.992 & 81.818 \\
\hline 1965 & 40.505 & 65.146 & 65.146 & -24.641 & 82.324 \\
\hline 1966 & 26.449 & 38.634 & 38.634 & -12.185 & 54.363 \\
\hline 1967 & 3.257 & & 7.785 & -4.528 & 17.012 \\
\hline 1968 & 23.220 & & 31.995 & -8.775 & 38.042 \\
\hline 1969 & 41.932 & & 50.086 & -8.154 & 59.273 \\
\hline 1970 & 40.552 & & 48.836 & -8.284 & 61.318 \\
\hline 1971 & 29.448 & & 37.530 & -8.082 & 52.434 \\
\hline 1972 & 22.463 & & 28.657 & -6.194 & 44.540 \\
\hline 1973 & 27.279 & & 30.441 & -3.162 & 46.234 \\
\hline 1974 & & & 1.206 & & 13.760 \\
\hline 1975 & & & 546 & & 7.606 \\
\hline Total & 408.811 & & 593.047 & -180.599 & 770.718 \\
\hline
\end{tabular}

Fuente: Ver Grafico 1 del artículo 


\section{APÉNDICE 2}

COMPARACION DEL FLUJO MIGRATORIO HACIA LA RFA DE HOMBRES Y MUJERES ESPAÑOLAS CON LAS CIFRAS DE EMIGRACIÓN ASISTIDA 1960-1973
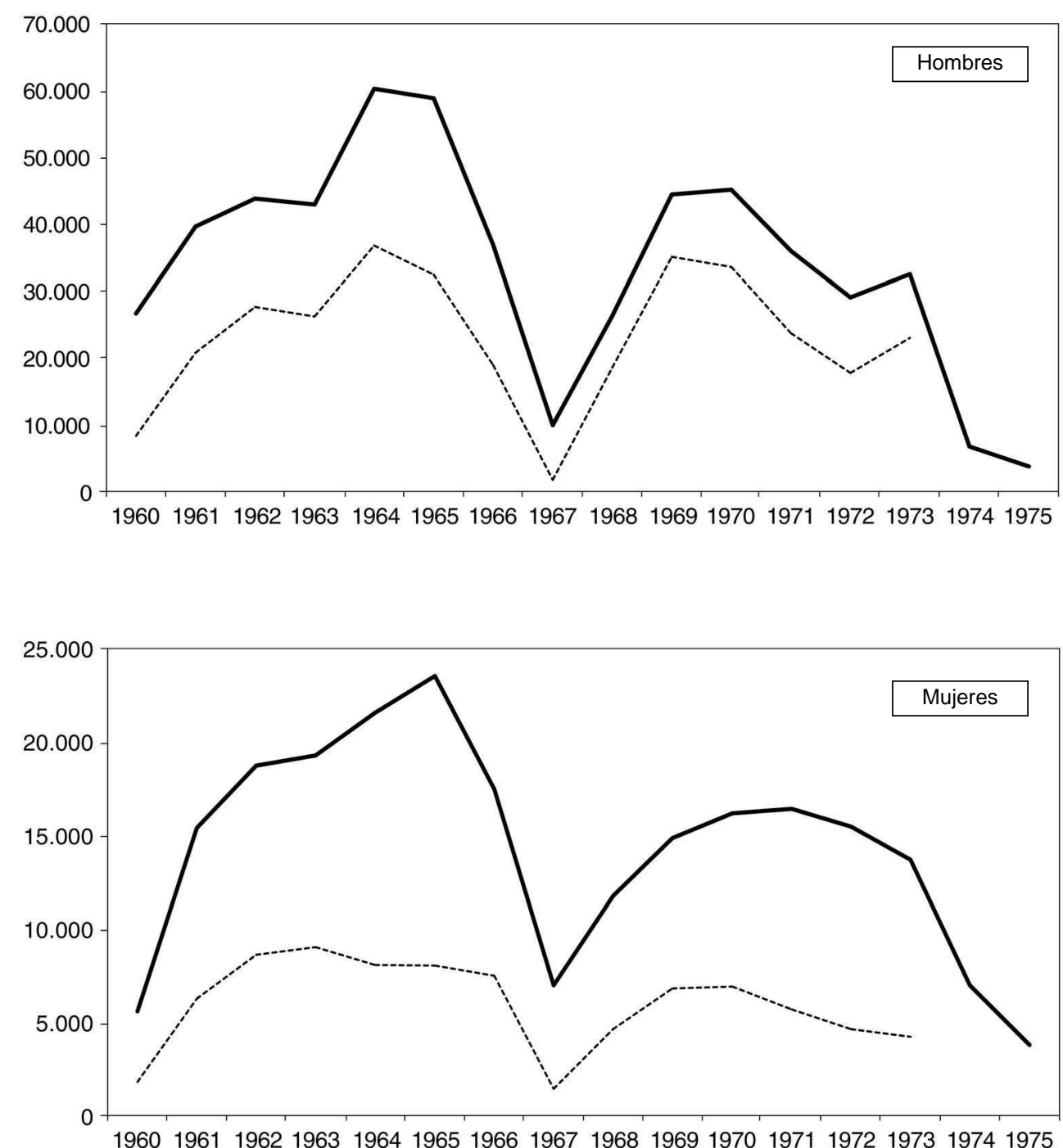

Fuente: Ver gráfico 1 del artículo 